Aus der Klinik für Dermatologie, Venerologie und Allergologie (Prof. Dr. med. M. P. Schön)

im Zentrum Arbeits-, Sozial-, Umweltmedizin und Dermatologie der Medizinischen Fakultät der Universität Göttingen

\title{
Immunomodulatory activity of murine keratinocyte-derived exosomes
}

\author{
INAUGURAL-DISSERTATION \\ zur Erlangung des Doktorgrades \\ der Medizinischen Fakultät der \\ Georg-August-Universität zu Göttingen \\ vorgelegt von \\ Kristina Kotzerke \\ aus \\ Hannover
}

Göttingen 2014 
Dekan:

1. Berichterstatter: $\quad$ Prof. Dr. med. M. P. Schön

2. Berichterstatter/in: Prof. Dr. rer. nat. H. M. Reichardt

3. Berichterstatter/in: Prof. Dr. rer. nat. P. Schu

Tag der mündlichen Prüfung: $\quad$ 20.01.2015 


\section{Content}

LIST OF TABLES.

LIST OF FIGURES........................................................................................................................

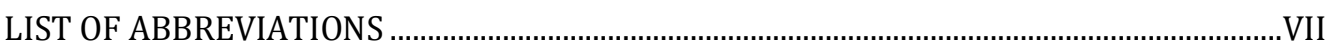

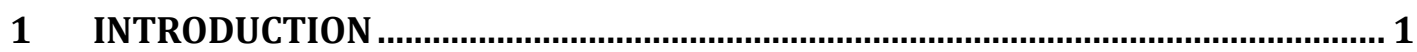

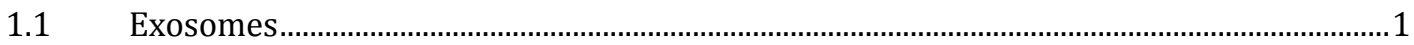

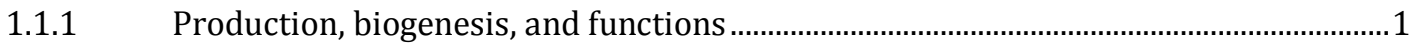

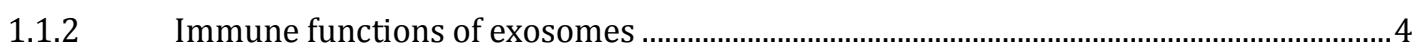

1.2 Keratinocytes and the cutaneous immune system ...........................................................

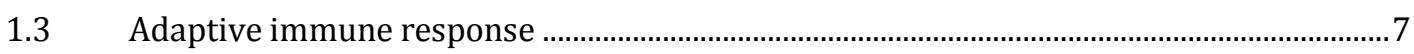

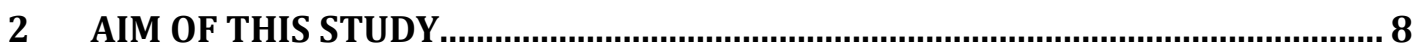

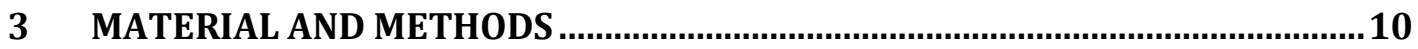

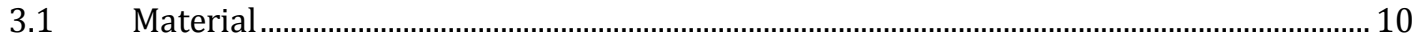

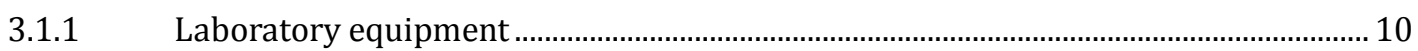

3.1.2 Disposables .................................................................................................... 11

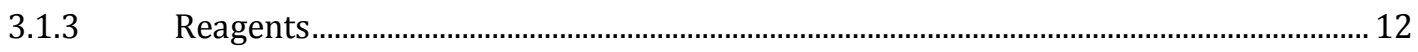

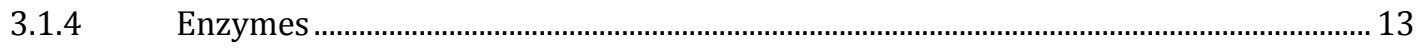

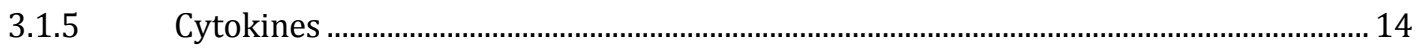

3.1.6 Antibodies directed against murine antigens ……...................................................... 14

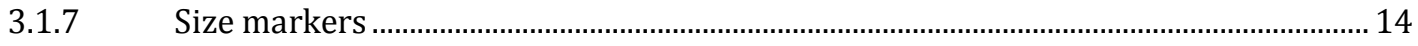

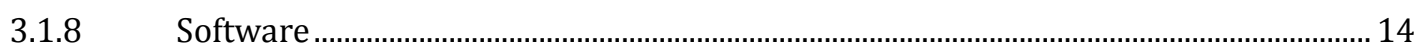

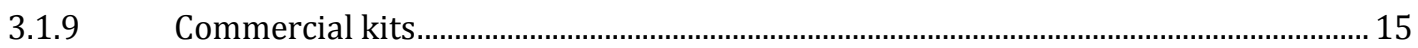

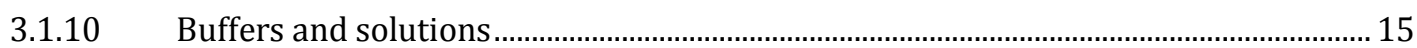

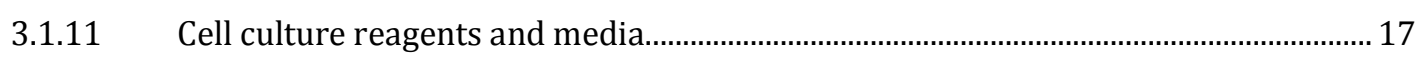

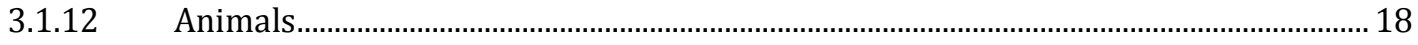

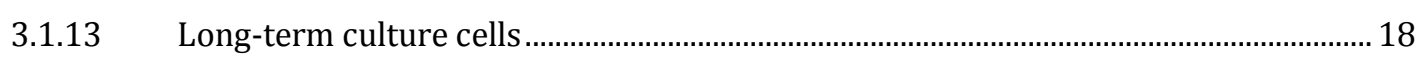

3.2 Methods

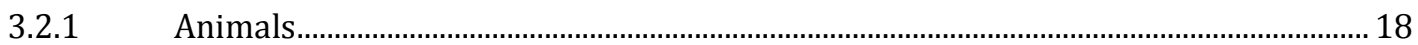

3.2.2 Cell culture (primary and long term) …………............................................................ 18

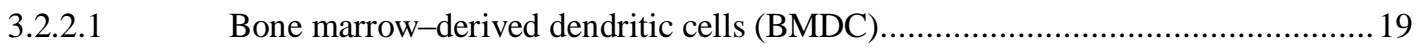

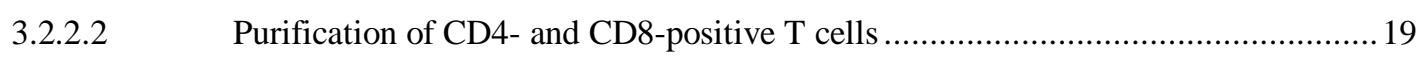

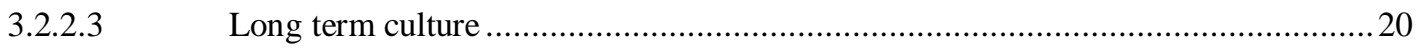

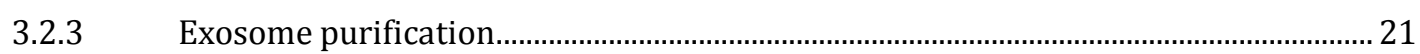

3.2.3.1 Density analysis of MPEK-derived membrane vesicles .....................................22

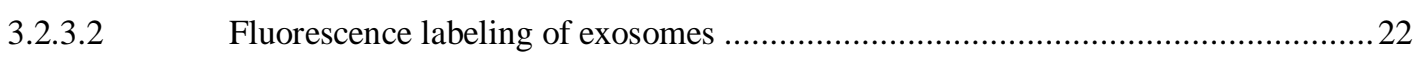

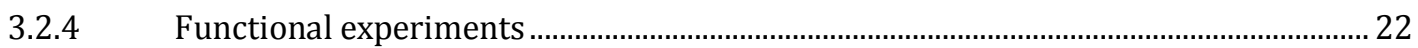




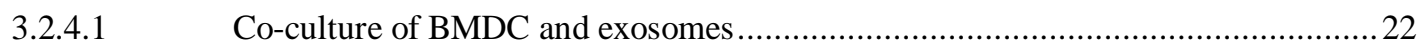

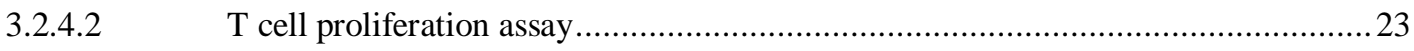

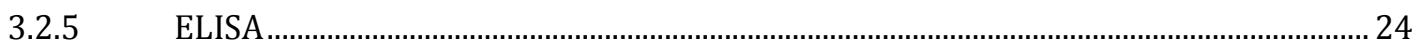

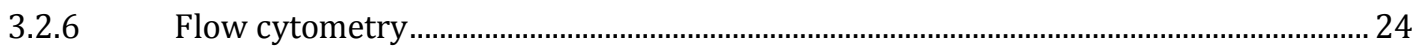

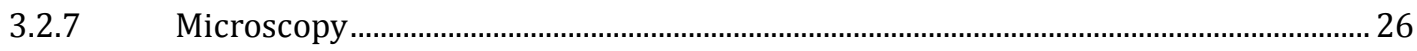

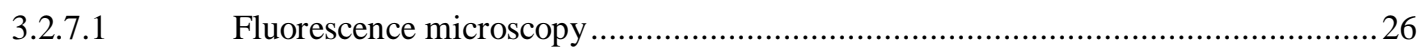

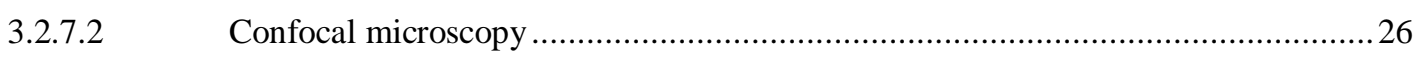

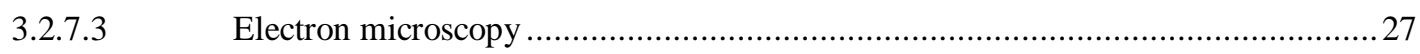

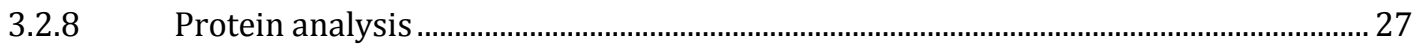

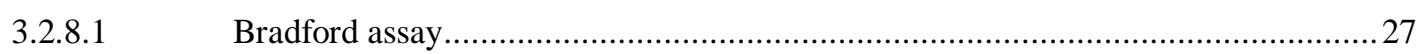

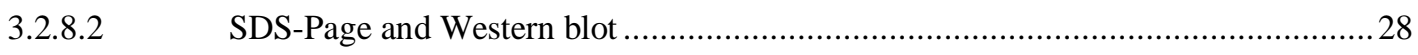

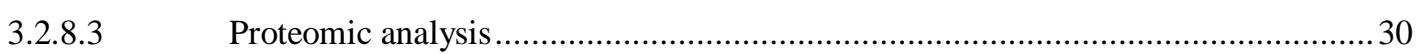

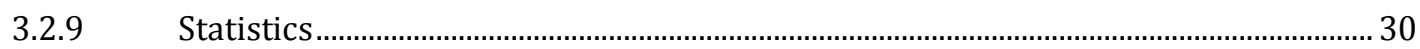

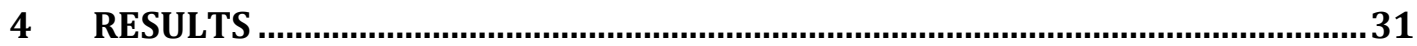

4.1 The murine kerationcyte cell line MPEK produces exosomes...........................................31

4.2 MPEK internalize antigen and shuttle it to their exosomes .................................................33

4.3 BMDC take up MPEK-derived exosomes with an increased quantity over time..............35

4.4 Exosome-uptake enhances production of IL-6, IL-10, and IL-12 and CD40 expression

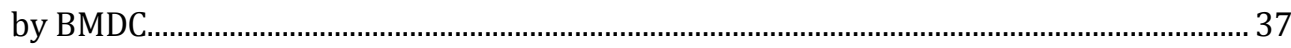

4.5 Antigen-containing exosomes fail to induce direct or BMDC-mediated antigen-specific T cell responses ................................................................................................................. 39

4.6 Composition of MPEK-derived exosomes is changed under defined conditions modeling clinical settings....................................................................................................... 42

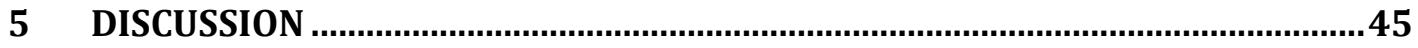

5.1 Characterization of MPEK-derived membrane vesicles ..................................................... 45

5.2 Immunological aspects of MPEK-derived exosomes .......................................................45

5.2.1 MPEK-derived exosomes contain antigenic information .............................................45

5.2.2 Immunostimulatory effect of MPEK-derived exosomes on BMDC............................... 46

5.2.3 Antigen-specific functions of MPEK-derived exosomes ............................................... 48

5.3 Bidirectional entanglement of environmental conditions and exosomal composition 49

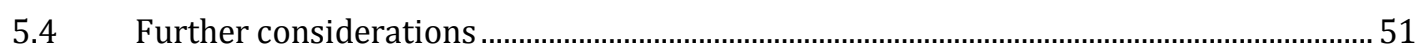

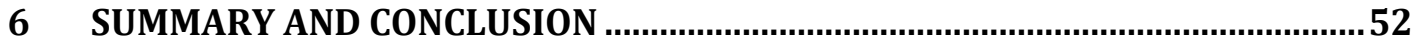

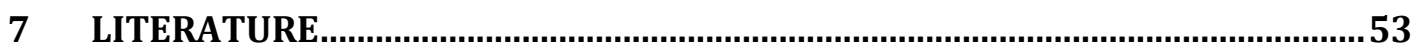

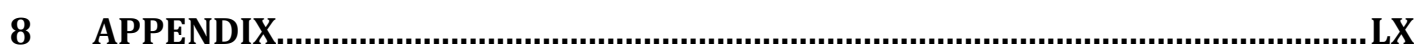

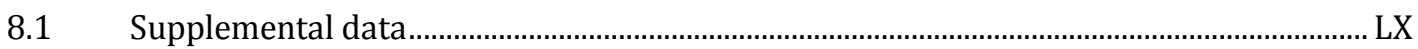

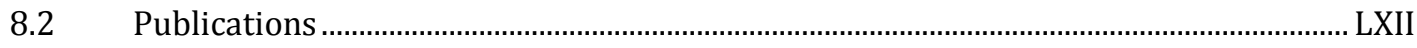

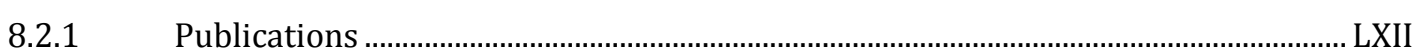

8.2.2 Presentations with published abstract................................................................... LXII 


\section{LIST OF TABLES}

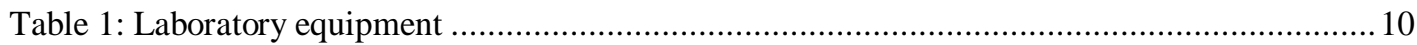

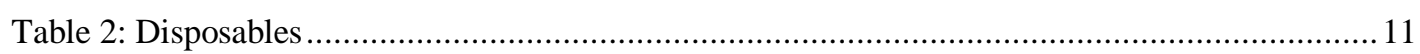

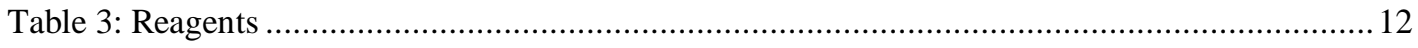

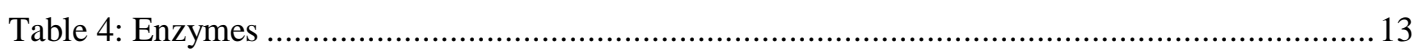

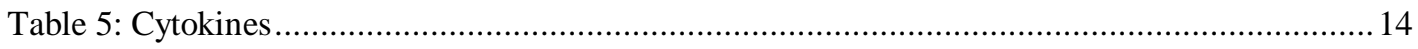

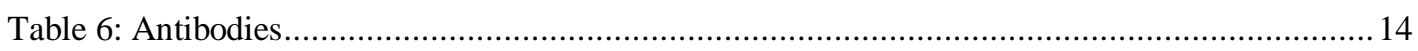

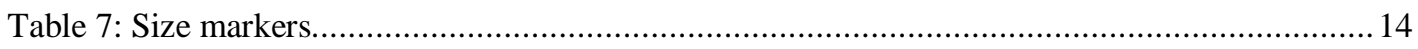

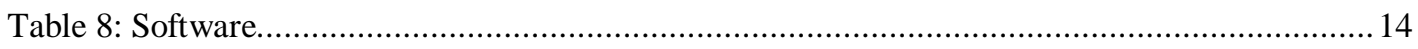

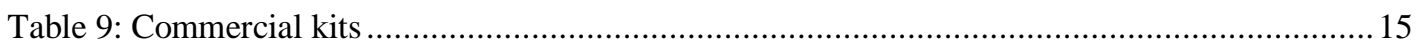

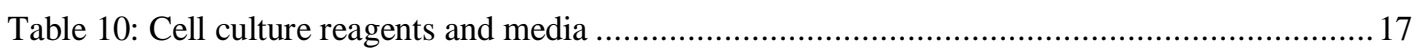

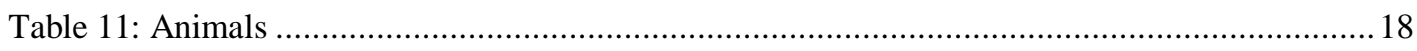

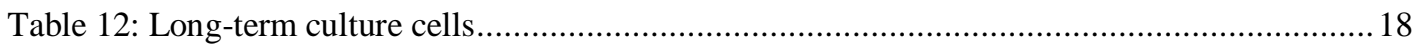

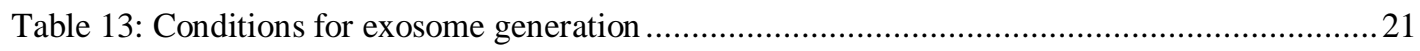

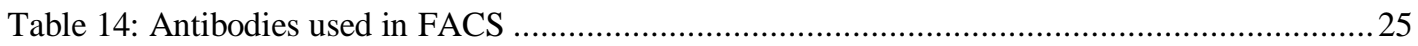

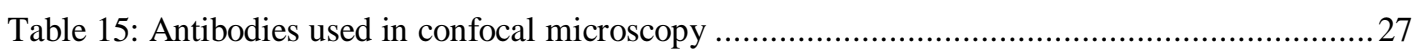

Table 16: Primary antibodies used in Western blot analysis ................................................29

Table 17: Secondary antibodies used in Western blot analysis ...................................................29

Table 18: Exosomal markers detected by proteomic analysis ........................................... 32

Table 19: MHC expression in MPEK-derived exosomes...........................................................40

Table 20: Exosomal composition under different environmental conditions ...............................43

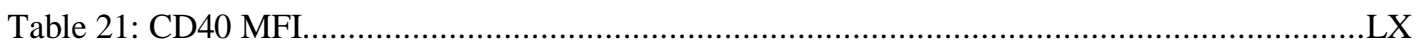

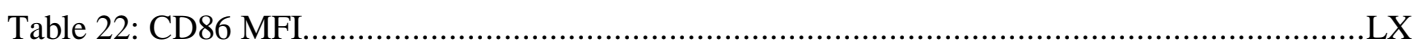

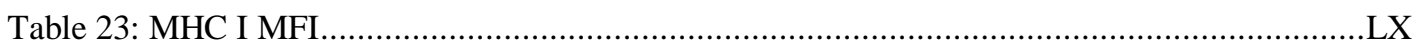

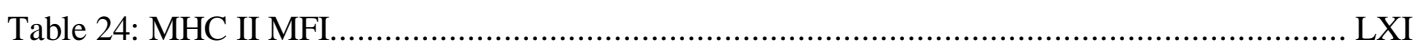

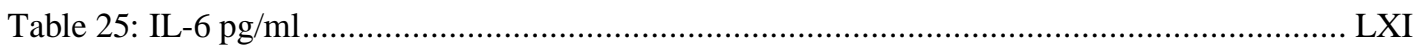

Table 26: IL-10 pg/ml ............................................................................................... LXI

Table 27: IL-12 pg/ml ..........................................................................................

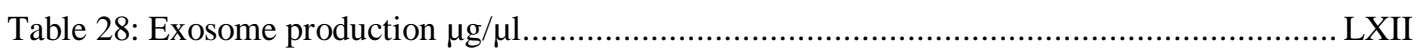




\section{LIST OF FIGURES}

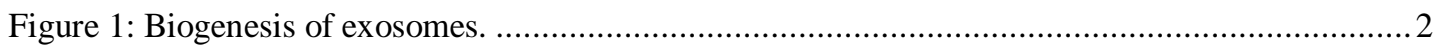

Figure 2: Keratinocytes are an integral component of the cutanous immune system...........................5

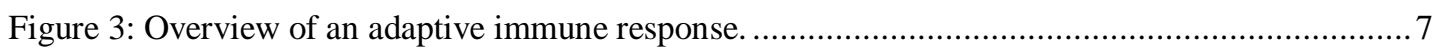

Figure 4: Hypothetic role of keratinocyte-derived exosomes in immune responses............................ 8

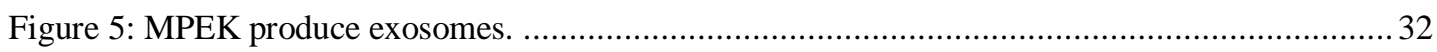

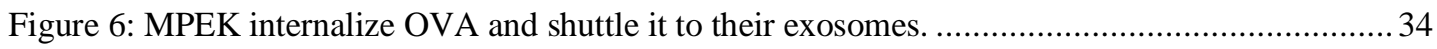

Figure 7: Uptake of MPEK-derived exosomes by BMDC increases over time...................................36

Figure 8: Exosome-loaded BMDC increase IL-6, IL-10, and IL-12 production and CD40

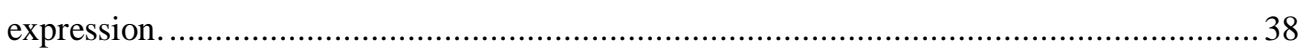

Figure 9: Antigen-loaded exosomes failed to induce antigen-specific $\mathrm{T}$ cell response directly or via BMDC 


\section{LIST OF ABBREVIATIONS}

APC

APC

APS

BMDC

cDNA

CFDA-SE

CFSE

DAPI

DC

DTT

ECL

EDTA

ELISA

EM

ESCRT

Exo

Exp

FACS

FCS

FITC

GM-CSF

HBSS

HEPES

HRP

IAA

IFN $\gamma$

IL

ILV

MACS

Med

MDDC

MFI

MHC

MPEK

MVB

NCBI
Antigen-presenting cell

Fluorophore: Allophycocyanin

Ammonium persulfate

Bone marrow-derived dendritic cell

Complementary deoxyribonucleic acid

Carboxyfluorescein diacetate succinimidyl ester

Carboxyfluorescein succinimidyl ester

4',6-diamidino-2-phenylindole

Dendritic cell

Dithiothreitol

Enhanced chemiluminescence

Ethylenediaminetetraacetate

Enzyme-linked Immunosorbent Assay

Electron microscopy

Endosomal sorting complexes required for transport proteins

Exosome

Experiment

Fluorescence activated cell sorting

Fetal calf serum

Fluorescein isothiocyanate

Granulocyte macrophage colony-stimulating factor

Hank's balanced salt solution

2-(4-(2-hydroxyethyl)-1-piperazineethanesulfonic acid

Horseradish peroxidase

Iodoacetamide

Interferon $\gamma$

Interleukin

Intraluminal vesicle

Magnetic cell separation

Medium

Monocyte-derived dendritic cell

Mean fluorescence intensity

Major histocompatibility complex

Murine epidermal keratinocyte progenitor cell

Multivesicular body

National Center for Biotechnology Information 
OVA

PAMPs

PBS

PE

PI

PRR

RNA

SDS

SDS-PAGE

TBS-T

TEMED

TLR

$\mathrm{TNF} \alpha$

WGA

\section{Ovalbumin}

Pathogen-associated molecular patterns

Phosphate buffered saline

Fluorophore: R-phycoerythrin

Propidium iodide

Pattern recognition receptor

Ribonucleic acid

Sodium dodecyl sulfate

SDS-Polyacrylamid gel electrophoresis

Tris-buffered saline-Tween 20

Tetramethylethylenediamine

Toll-like receptor

Tumor necrosis factor $\alpha$

Wheat germ agglutinin 


\section{Introduction}

\subsection{Exosomes}

Exosomes are small membrane vesicles of endocytic origin. They have been described for the first time thirty years ago. Early research focusing on reticulocyte maturation and investigation of the destiny of the transferrin receptor discovered accumulation of transferrin receptors in multivesicular bodies and proposed the transferrin receptor to be externalized in $50 \mathrm{~nm}$-vesicles (Harding et al. 1983; Pan and Johnstone 1983). These small exocytosed membrane vesicles were termed exosomes (Johnstone et al. 1989). For specification of usage, exosomes are defined by three main characteristics: a saucer-like shape and size of $40-100 \mathrm{~nm}$ as determined by electron microscopy, a density of $1.10-1.23 \mathrm{~g} / \mathrm{ml}$ in a sucrose gradient, and the presence of certain exosomal markers including alix, tsg101, CD81, and flotillin. These markers belong to different protein groups involved in targeting, signaling, or fusion. One of the major protein groups found in exosomes are the so called tetraspanins like CD 81 (Mathivanan et al. 2012; Thery et al. 2002). A new great interest on exosomes arose about ten years later, when it was discovered that exosomes are involved in immunological processes (Raposo et al. 1996). Since this outstanding discovery, the role of exosomes has been addressed in several studies in vitro and in vivo.

\subsubsection{Production, biogenesis, and functions}

A variety of cell types produces exosomes: hematopoietic cells such as dendritic cells, mast cells, B and T cells (Thery et al. 2002) and also non-hematopoietic cells such as intestinal epithelial cells (van Niel et al. 2001), human keratinocytes (Chavez-Muñoz et al. 2008), and solid tumor cells (Xiao et al. 2012). Exosomes have even been discovered in vivo in body fluids such as blood (Caby et al. 2005), urine (Zhou et al. 2006), and bronchoalveolar lavage (Admyre et al. 2003). The biogenesis of exosomes itself has not yet been fully understood and still requires 
further clarification regarding its details. Yet, a substantial body of evidence has accumulated that provides insight into the main principles of exosome biogenesis: Eukaryotic cells hold a highly developed endosomal network to link synthesis, transport, and fusion processes. Early endosomes are membrane-bound organelles that either gather endocytosed material from the plasma membrane or synthesized proteins from the Golgi complex. These early endosomes are able to transform to multivesicular bodies (MVB), sometimes also referred to as late endosomes or multivesicular endosomes, through inward budding of their membrane and forming small intraluminal vesicles (ILV). Evidence suggests the existence of different subpopulations of MVB, differing in destinations. MVB can either be directed to fuse with lysosomes for degradation or to fuse with the cells' plasma membrane exocytosing its vesicles. These small exocytosed membrane vesicles are referred to as exosomes (Fig. 1).

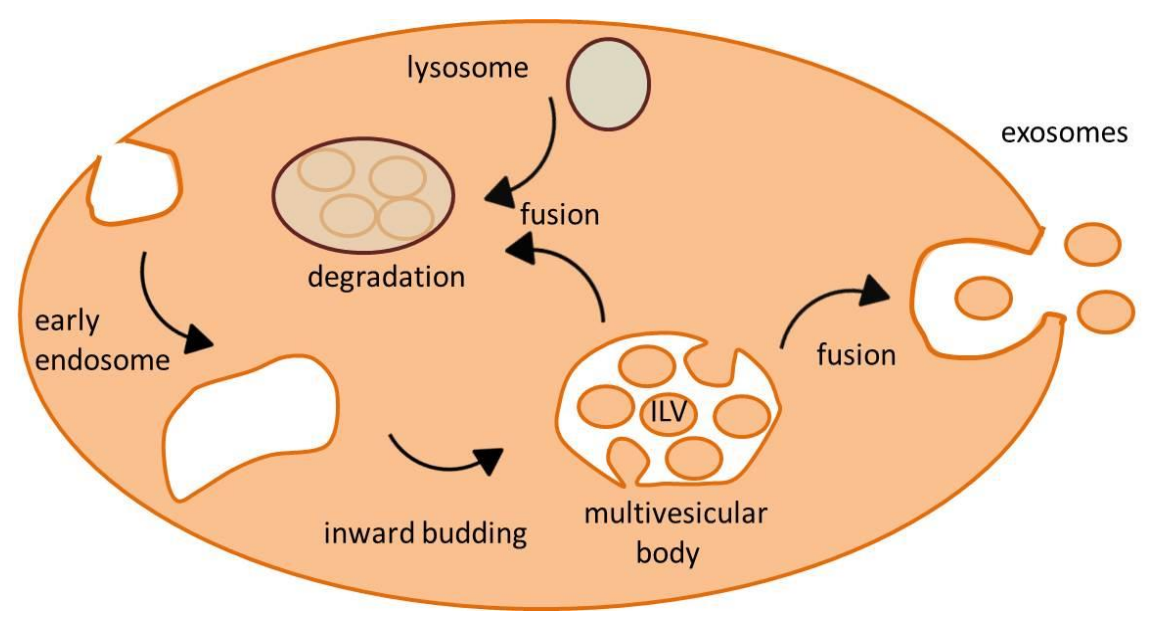

Figure 1: Biogenesis of exosomes. Early endosomes transform to multivesicular bodies by inward budding of their membrane and forming small intraluminal vesicles. Multivesicular bodies either fuse with lysosomes and are degraded or they fuse with the cell membrane and exocytose their vesicles. These exocytosed membrane vesicles are referred to as exosomes.

Due to the mechanism of emergence, exosomes contain material of the cytoplasm and the same membrane orientation as the cell itself, representing a cell in miniature format with regard to its structure and lipid bilayer (Lakkaraju and Rodriguez- 
Boulan 2008). However, exosomes can be enriched with certain cargoes in comparison to their mother cells and do not contain the exact same protein composition (Ratajczak et al. 2006). A pivotal role in the process of biogenesis has been ascribed to the different endosomal sorting complexes required for transport (ESCRT) proteins. These complexes engineer inward budding of vesicles, cluster marked proteins, and package those proteins into the formed ILV. Alix, often used as classical exosomal marker, holds a linker role between the different ESCRT proteins and might also be involved in the generation of intraluminal vesicles (Babst 2005).

During the years following first discovery, exosomes attracted more and more notice. It became clear that the idea of exosomes functioning as the garbage system of the cell by externalizing obsolete proteins was only one of various functions. As exosomes contain a certain set of exosome-specific proteins, they additionally contain a special set of proteins depending on the cell type they originate from (Simpson et al. 2008). Secreted exosomes can be internalized by other cells (Morelli et al. 2004) and even a specific uptake and target selection has been suggested (Rana and Zoller 2011). Consequently, exosomes can be considered as a non-classical way of protein secretion and delivery and as a mediator of communication without direct cell-cell contact. By influencing cell-to-cell communication, exosomes are also able to affect and direct immune processes. Further, the enrichment of certain proteins in exosomes qualifies them as usable biomarkers for diseases like Alzheimer`s disease (Cogswell et al. 2008), Sjögren`s syndrome (Michael et al. 2010) and especially for certain tumor diseases, as exosomes are produced by a variety of tumor cells (Simpson et al. 2009). Different studies focusing on dendritic cell-derived exosomes established a revolutionary therapy option using exosomes as vaccine in immunotherapy against cancer (Viaud et al. 2010). Lately, different groups were able to demonstrate the transfer of microRNA and messengerRNA in exosomes, even broadening the understanding of exosomes' functions to the possibility of genetic exchange (Valadi et al. 2007). Unfavorably, as exosomes deliver information and proteins to different $\mathrm{T}$ cells, they can also spread diseases by transporting infectious cargoes such as viruses or prions 
(Fevrier et al. 2004; Nguyen et al. 2003). Besides the above-mentioned functions - communication, immune modulation, biomarker, immunotherapy, transfer of mRNA, transfer of infectious cargo - exosomes might exert additional, yet unknown, functions and further research will be needed for clarification.

\subsubsection{Immune functions of exosomes}

The strong interest in immunological capacities of exosomes arose in the late nineties with the discovery of $\mathrm{B}$ cells presenting antigens via their exosomes (Raposo et al. 1996). Subsequent research demonstrated antigen-presenting cell-derived (APC-derived) and tumor-derived exosomes to carry antigenic peptide-loaded MHC I and MHC II molecules and to induce antigen-specific T cell responses in vitro and in vivo (Chaput and Thery 2011; Thery et al. 2009; Zitvogel et al. 1998). Even though some exosomes are able to directly interact with T cells to elicit immune responses (van Niel et al. 2003), others depend on the presence of APC (Skokos et al. 2001). Further, it is believed that immature DC transfer processed antigen-MHC complexes via exosomes to other DC, spreading antigenic information and multiplying the number of effective APC (Pant et al. 2012). However, the way how exosomes influence immune reactions strongly depends on the maturation and stimulation stage of the parent cell they are derived of and the cell lineage itself (Viaud et al. 2010). These aspects lead either to pro-inflammatory responses as for example demonstrated for B cell-derived and APC-derived exosomes (Admyre et al. 2007; Kovar et al. 2006) or to anti-inflammatory responses as demonstrated for exosomes found in bronchoalveolar lavage of tolerized mice (Prado et al. 2008) or for exosomes derived from serum to treat arthritis (Yang and Robbins 2012). Since most research has been conducted with professional APC it will be interesting to broaden immunological aspects of exosomes by focusing on exosomes derived from non-professional APC as keratinocytes. 


\subsection{Keratinocytes and the cutaneous immune system}

Keratinocytes, constituting the majority of epidermal cells, form a firm united multicellular structure, building up a barrier to environmental influences. Besides the physical barrier to pathogenic microbes, keratinocytes express MHC I and a subset of so called toll-like receptors (TLR), belonging to the group of pattern recognition receptors (PRRs). This kind of receptors is activated by certain components of microbial pathogens named pathogen-associated molecular patterns (PAMPs) (Mempel et al. 2007). The activation of TLRs through pathogens induces an intracellular cascade leading to the production of chemokines and cytokines. Those chemokines, in turn, recruit further immune competent cells such as neutrophils to eliminate invading pathogens or at least to prevent their spreading (Iwasaki and Medzhitov 2004). Additionally, keratinocytes form a chemical barrier through the production of antimicrobial lipids. By means of those antimicrobial peptides including defensins, cathelicidins, and RNase7, they are able to kill or inactivate a variety of microorganisms (Pivarcsi et al. 2005) (Fig. 2).

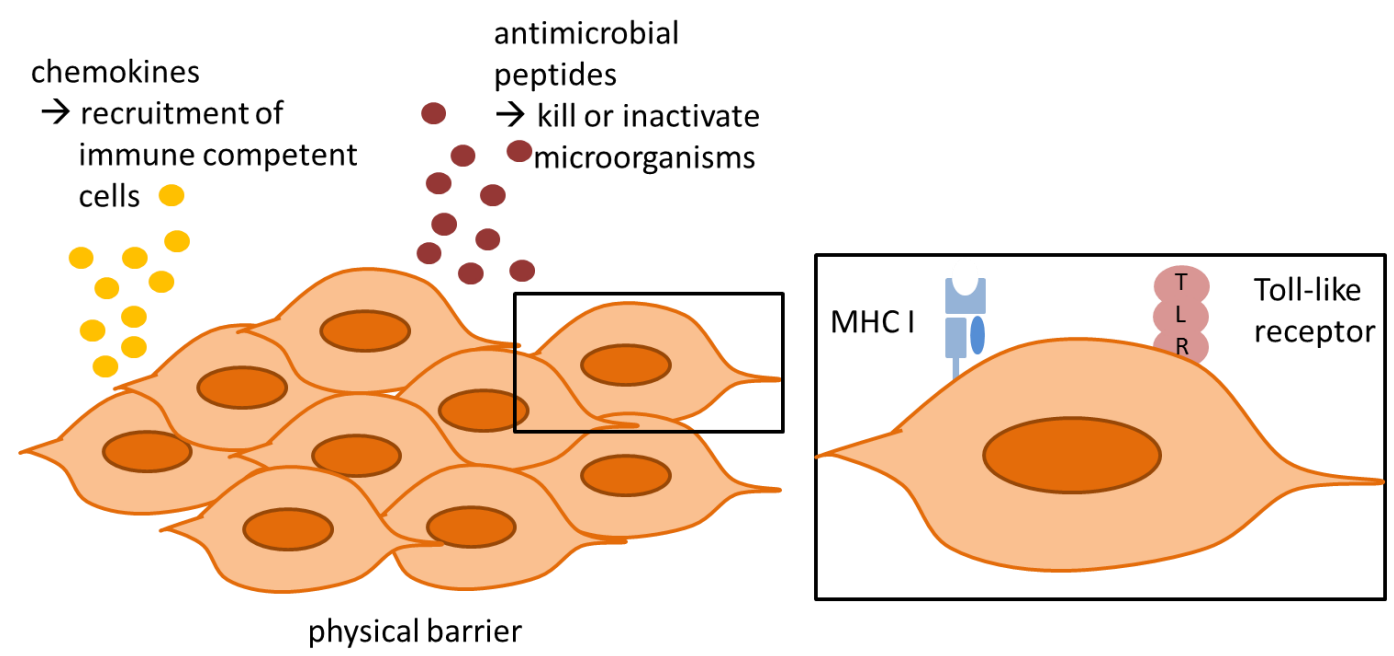

Figure 2: Keratinocytes are an integral component of the cutanous immune system. Keratinocytes express MHC I and a subset of toll-like receptors. Through activation of these receptors, keratinocytes produce different chemokines to recruit immune competent cells. Further, keratinocytes are able to kill or inactivate microorganisms with antimicrobial peptides. 
Besides the pivotal role of keratinocytes for cutaneous innate immunity, an important contribution to adaptive immune responses is discussed. Keratinocytes constitutively express MHC I but no MHC II. However, inflammatory conditions (IFN $\gamma$ ) induce keratinocytes to express MHC II and to function as so called non-professional APC, providing co-stimulatory signals to T cells (Nickoloff and Turka 1994). These findings are supported by the discovery that keratinocytes function as accessory APC in vitro and in vivo irrespective of the presence or absence of professional APC (Kim et al. 2009). Moreover, it has been shown that keratinocytes are able to take up antigen, to efficiently process it, and to present it to CD4-positive and CD8-positive memory $\mathrm{T}$ cells, thus inducing an immune response (Black et al. 2007; Blume et al. 2009). 


\subsection{Adaptive immune response}

Keratinocytes accomplish a main task of the cutaneous innate immunity. With the discovery of keratinocytes functioning as non-professional APC, research started to focus on their ability to direct adaptive immune responses. Classically adaptive immune responses are induced by professional APC. In the skin, Langerhans cells fulfill this task (Banchereau and Steinman 1998). Immature dendritic cells have a high phagocytotic activity, thus they efficiently internalize antigen. Uptake of antigen leads to maturation, lowers phagocytotic activity, and increases the expression of co-stimulatory molecules such as CD40 or CD86. The internalized antigen is processed and presented mainly via MHC II to CD4-positive T cells but also by cross-presentation via MHC I to CD8-positive T cells, inducing an antigenspecific T cell response (Mellman and Steinman 2001) (Fig. 3).

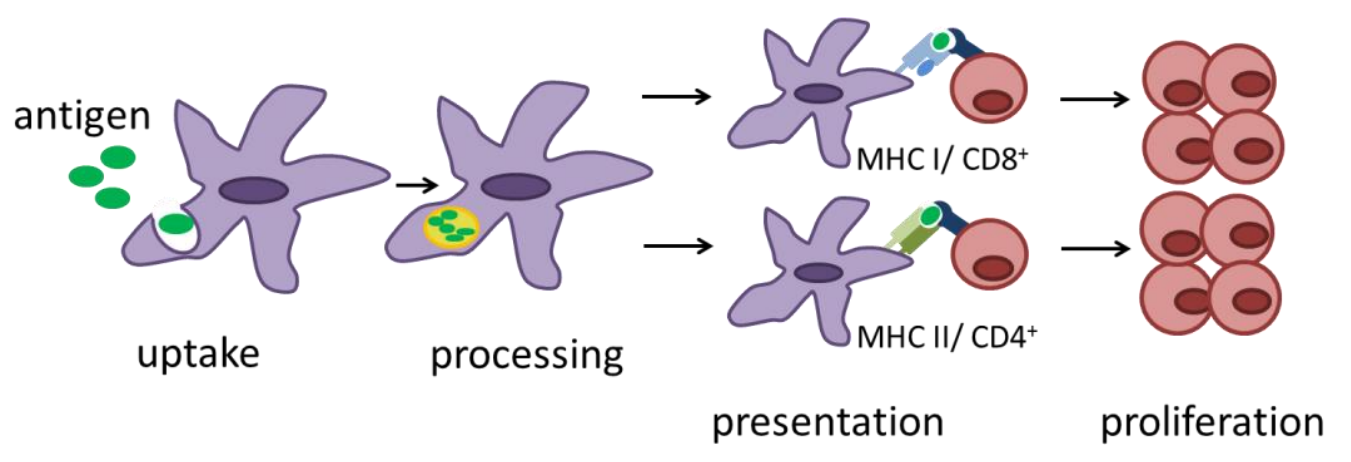

Figure 3: Overview of an adaptive immune response. APC take up antigen, process it, and present it via MHC II to CD4-positive T cells or as cross-presentation via MHC I to CD8-positive $\mathrm{T}$ cells, inducing and antigen-specific $\mathrm{T}$ cell response. 


\section{Aim of this study}

Research into the (patho)-physiology of exosomes has focused primarily on exosomes derived from hematopoetic cells (Thery et al. 2002). Hence, data on exosomes of epithelial cells such as keratinocytes are scant (Chavez-Muñoz et al. 2008; Chavez-Muñoz et al. 2009; Sanderson et al. 2008). The aim of this study was to explore keratinocyte-derived exosomes as a new mechanism for keratinocytes to influence immunity. As keratinocytes are organized in a firm polarized epithelial tissue structure, they only have a close range to present antigen to other cells when acting as non-professional APC. To expand their range of communication with other cells, keratinocyte-derived exosomes could serve as an additional mechanism to spread antigenic information to certain cells beyond their immediate reach. Experimental evidence suggests that the uptake of exosomes is a non-random event influenced by the presence of certain tetraspanins as uptake selection markers (Rana and Zoller 2011). Consequentely, keratinocytes could take up antigen and transfer it to their exosomes. These antigen-loaded exosomes could be taken up by dendritic cells and influence their cytokine profile or maturation state. Further, antigen-containing exosomes internalized by dendritic cells could be presented to antigen-specific T cells and elicit antigen-specific proliferation (Fig. 4).

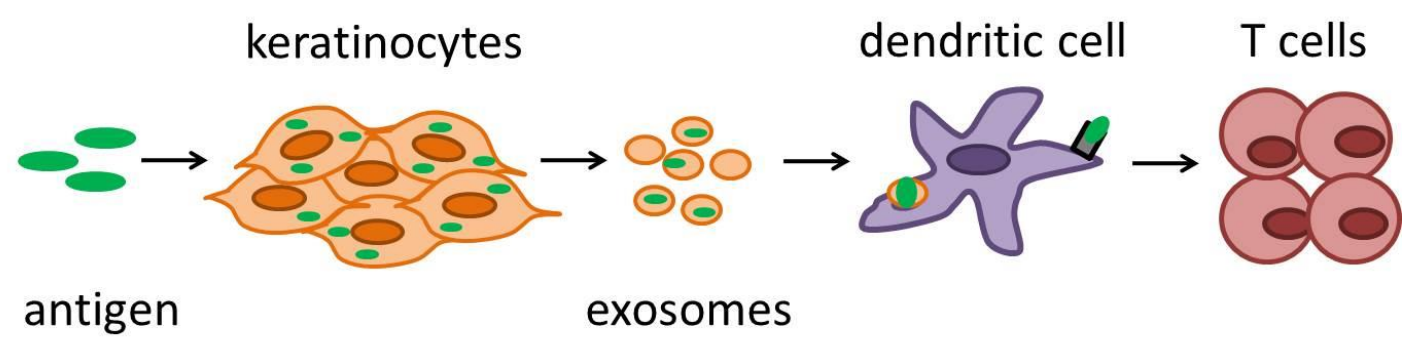

Figure 4: Hypothetic role of keratinocyte-derived exosomes in immune responses. Keratinocytes take up antigen and transfer it to their exosomes. These antigen-containing exosomes then become internalized by dendritic cells and elicit an antigen-specific $\mathrm{T}$ cell response when presented. 
In reverse, to address the mutual influence of exosomes and their environment, the influence of environmental conditions on exosome composition should also be explored. As frequent chronic diseases, the pathologically altered cytokine environments in psoriasis and atopic dermatitis appear suitable for this investigation (Bieber 2012; Raychaudhuri 2012). Toward this end, the follwing questions should be answered to address the immunlogical role of keratinocyte-derived exosomes:

- Do keratinocytes transfer internalized antigen to their exosomes?

- Do these exosomes influence the maturation state and interleukin profile of bone marrow-derived dendritic cells (BMDC)?

- Are antigen-containing exosomes able to elicit an antigen-specific T cell response via BMDC?

- Do environmental conditions influence the composition of keratinocyte derived exosomes? 


\section{Material and Methods}

\subsection{Material}

\subsubsection{Laboratory equipment}

Table 1: Laboratory equipment

\begin{tabular}{|c|c|}
\hline Laboratory equipment & Company \\
\hline Appliskan Multimode Microplate Reader & Thermo Scientific \\
\hline Autoclave & Sanyo \\
\hline BD FACSCanto II & BD Bioscience \\
\hline Beckman optima LE 30K ultracentrifuge & Beckman Coulter GmbH \\
\hline bucket rotor $\mathrm{Sw} 32 \mathrm{Ti}$ & Beckman Coulter GmbH \\
\hline Centrifuge Multifuge 15-R & Heraeus \\
\hline Centrifuge Pico 17 & Heraeus \\
\hline Centrifuge Rotina 35 & Hettich Zentrifugen \\
\hline CM120 electron microscope & Philips \\
\hline $\mathrm{CO}_{2}$ incubator HERAcell $150 \mathrm{i}$ & Thermo Scientific \\
\hline Confocal microscope Olympus Fluoview 1000, & Olympus \\
\hline Copper grid & Plano \\
\hline Cytospin 2 centrifuge & Shandon \\
\hline Double distilled water system arium ${ }^{\circledR} 611 \mathrm{VF}$ & Sartorius \\
\hline Electrophoresis Power Supply-EPS 1001 & Amersham Biosciences \\
\hline Heating block Thermo Stat plus & Eppendorf \\
\hline Incubator HERAcell 150 & Thermo Scientific \\
\hline Incubator HERAcell 150i & Thermo Scientific \\
\hline iTEM-Camera & Olympus \\
\hline LAS-4000 imaging system & Fujifilm \\
\hline LTY Orbitrab XL hybrid mass spectrometer & Thermo Scientific \\
\hline MACS MultiStand & Miltenyi \\
\hline MidiMACS Separator & Miltenyi \\
\hline Magnet stirrer & VWR \\
\hline Micro scale ALC & Acculab \\
\hline Microcentrifuge & Sprout \\
\hline Microscope Axio Imager M1 & Zeiss \\
\hline Microscope Axiovert 40 & Zeiss \\
\hline Nanoflow LC system & Agilent \\
\hline Neubauer counting chamber & Brand \\
\hline pH-meter FE20-Five easy ${ }^{\mathrm{TM}}$ & Mettler Toledo \\
\hline Photometer Genesys 10 Bio & Thermo Scientific \\
\hline Pipetboy acu & IBS Integra Biosciences \\
\hline
\end{tabular}


Pipette set: 1000, 100, and $10 \mu \mathrm{l}$

PowerPac Basic

Refrigerated centrifuge

Refrigerator and freezer $+4^{\circ} \mathrm{C},-20^{\circ} \mathrm{C},-80^{\circ} \mathrm{C}$

Roborack-96

Roborack-96 cover

Rocking platform Polymax 1040

Scale precision

Scale Vicon

Shaker

See-saw rocker SSL4

Sonorex RK 100 Transistor

Spectrometer Genesys 10Bio

Sterile bench HERAsafe

Sterile bench Safe 2020

Thermal mixer ThermoStat plus

Trans -Blot SD semi-dry transfer cell

Vacusafe comfort

Vertical electrophoresis system Mini-

PROTEAN®TetraCell

Vortex L46

Water bath
Eppendorf

Bio-Rad

Eppendorf

Liebherr

Micronic

Micronic

Heidolph

Sartorius

Acculab

Grant-bio

Stuart

Bandelin

Thermo Scientific

Thermo Scientific

Thermo Scientific

Eppendorf

Bio-Rad

IBS Integra Biosciences

Bio-Rad

Labinco

Memmert

\subsubsection{Disposables}

Table 2: Disposables

\begin{tabular}{ll}
\hline Disposable/ Material & Company \\
\hline 6-well plates & Greiner Bio One \\
8-well CultureSlides & BD Bioscience \\
96-well plates U bottom & Nunc \\
Cell culture flasks $175 \mathrm{~cm}^{3}$ & Sarstedt \\
Cell strainer $70 \mu \mathrm{m}$ & BD Bioscience \\
Chromatography paper Whatman ${ }^{\mathrm{TM}}$ & GE Healthcare \\
Cover glasses, $24 \mathrm{x} 60 \mathrm{~mm}$ & Menzel-Gläser \\
FACS tubes $5 \mathrm{ml}$ & BD Bioscience \\
Eppendorf tubes $0.5 \mathrm{ml}, 1.5 \mathrm{ml}, 2.0 \mathrm{ml}$ & Eppendorf \\
Falcon tubes $15 \mathrm{ml}, 50 \mathrm{ml}$ & Greiner Bio-One \\
Filter V50 0,2 $\mu \mathrm{m}$ & Sarstedt \\
Macs LS Columns & Miltenyi \\
Needle Microlance 3 & BD Bioscience \\
Nitrocellulose membrane & Bio-Rad \\
Nunc® Sealing tape for multiwell plates & Sigma-Aldrich \\
Perfusor@ syringe, $50 \mathrm{ml}$ & B. Braun \\
Petri dish $35 \mathrm{x} 10$ & Nunc
\end{tabular}


Pipette tips 1000, 200, and $10 \mu \mathrm{l}$

Plastic pipettes $25 \mathrm{ml}, 10 \mathrm{ml}, 5 \mathrm{ml}$

Plastic cuvettes

Polypropylene tubes, $1.3 \mathrm{ml}$

Pre-separation filters $30 \mu \mathrm{m}$

Reaction cups $2 \mathrm{ml}, 1.5 \mathrm{ml}$ and $0.5 \mathrm{ml}$

Syringe $1 \mathrm{ml}$ Omnifix 40 solo

TechnoCut scalpel

Tube, round bottom, $1.3 \mathrm{ml}$

Tube, thinwall, ultra clear $38.5 \mathrm{ml}$

UpCell Surface cell culture dish 92 x $17 \mathrm{~mm}$
Starlab

Sarstedt

Sarstedt

Greiner

Miltenyi

Eppendorf

B. Braun

HMD Healthcare

Greiner

Beckman Coulter

Nunc

\subsubsection{Reagents}

Table 3: Reagents

\begin{tabular}{|c|c|}
\hline Reagent & Company \\
\hline 4',6-diamidino-2-phenylindole (DAPI) & Sigma-Aldrich \\
\hline 7x Protease inhibitor cocktail & Roche \\
\hline Acetic acid & Merck \\
\hline Acetone & Roth \\
\hline Acrylamide/ Bis-acrylamide, $30 \%$ solution & Bio-Rad \\
\hline Ammonium chloride & Merk \\
\hline Ammonium persulfate & Gibco \\
\hline BGG protein standards $0.125-1.5 \mathrm{mg} / \mathrm{ml}$ & Fermentas \\
\hline Bio-Rad protein assay dye & Bio-Rad \\
\hline Boric acid & Roth \\
\hline Bovine serum albumin & Roth \\
\hline Bradford Reagent & Bio-Rad \\
\hline Bromophenol blue & Sigma-Aldrich \\
\hline BSA Standards, ready to use & Fermentas \\
\hline Calcium chloride $\left(\mathrm{CaCl}_{2}\right)$ & Roth \\
\hline CFDA-SE & Invitrogen \\
\hline Citric acid & Roth \\
\hline Coomassie Brilliant Blue (triphenylmethane) & Bio-Rad \\
\hline $\mathrm{D}(+)$ saccharose & Roth \\
\hline DMSO (Dimethyl sulfoxide) & Sigma-Aldrich \\
\hline DTT (Dithiothreitol) & Roth \\
\hline Ethanol & Roth \\
\hline EDTA (Ethylenediaminetetraacetic acid) & Roth \\
\hline FACS Clean solution & BD Bioscience \\
\hline FACS Shutdown Solution & BD Bioscience \\
\hline Fluorescence Mounting Medium & Dako \\
\hline Glycine & Merck \\
\hline Glutaraldehyde & Electron Microscopy Science \\
\hline
\end{tabular}


Hydrochloric acid $(\mathrm{HCl})$

Hydrogen peroxide $\left(\mathrm{H}_{2} \mathrm{O}_{2}\right)$

IAA (indole-3-acetic acid)

Luminol

Magnesium chloride $\left(\mathrm{MgCl}_{2}\right)$

Methanol

Non-fat dry milk (NFDM)

NP-40

NuPAGE Bis-Tris Gel 4-12\%

Ovalbumin grade $\mathrm{V}$

Ovalbumin purified

Ovalbumin conjugate FITC

p-Coumaric acid

Paraformaldehyde

Ponceau S

Potassium chloride $(\mathrm{KCl})$

Potassium hydroxide $(\mathrm{KOH})$

Potassium dihydrogen phosphate $\left(\mathrm{KH}_{2} \mathrm{PO}_{4}\right)$

Propidium iodide

Restore Western Blot Stripping Buffer

Sodium azide $\left(\mathrm{NaN}_{3}\right)$

Sodium chloride $(\mathrm{NaCl})$

Sodium hydrogen carbonate

Sodium hydrogen phosphate

Sodium n-dodecyl sulfate (SDS)

Stripping buffer

Sulfuric acid $\left(\mathrm{H}_{2} \mathrm{SO}_{4}\right)$

Tetramethylethylbenzidine (TMB)

Tetramethylethylenediamine (TEMED)

TRIS

TRIS-HCl

Triton X-100

Trypan blue

Trypsin-EDTA $0.05 \% / 0.02 \%$

Trypsin-Inhibitor

Tween-20

Uranyl acetate
Roth

Roth

Sigma

Sigma

Merck

Merck

Bio-Rad

USB

Invitrogen

Sigma

Worthington

Molecular probes

Sigma

Roth

Sigma-Aldrich

Roth

Merck

Merck

Roth

Thermo Scientific

Merck

Merck

Roth

Roth

Calbiochem

Thermo Scientific

Roth

Roth

Merck

Roth

Roth

Merck

Sigma

Roth

Roth

Sigma

\subsubsection{Enzymes}

\section{Table 4: Enzymes}

\begin{tabular}{ll}
\hline Enzym & Company \\
\hline Collagenase D & Roche \\
DNAse & Roche
\end{tabular}




\subsubsection{Cytokines}

Table 5: Cytokines

\begin{tabular}{lcl}
\hline Cytokine & Concentration used & Company \\
\hline IFN $\gamma$ & $50 \mathrm{ng} / \mathrm{ml}$ & BioLegend \\
IL-2 & $10 \mathrm{ng} / \mathrm{ml}$ & BioLegend \\
IL-4 & $10 \mathrm{ng} / \mathrm{ml}$ & BioLegend \\
IL-13 & $50 \mathrm{ng} / \mathrm{ml}$ & Immunotools \\
IL-17 & $10 \mathrm{ng} / \mathrm{ml}$ & Immunotools \\
IL-22 & $50 \mathrm{ng} / \mathrm{ml}$ & BioLegend \\
TNF $\alpha$ & $25 \mathrm{ng} / \mathrm{ml}$ & Immunotools
\end{tabular}

\subsubsection{Antibodies directed against murine antigens}

Table 6: Antibodies

\begin{tabular}{lcl}
\hline Antibody & Concentration used & Company \\
\hline CD3 $\varepsilon$ & $1 \mu \mathrm{g} / \mathrm{ml}$ & eBioscience \\
CD4 (L3T4), MicroBeads & $10 \mu \mathrm{l} / 10^{7}$ cells & Miltenyi \\
CD8a (Ly-2), Micro Beads & $10 \mu \mathrm{l} / 10^{7}$ cells & Miltenyi \\
CD28 & $1 \mu \mathrm{g} / \mathrm{ml}$ & eBioscience
\end{tabular}

Antibodies used in flow cytometry, fluorescence and confocal microscopy, and Western blot are stated within the corresponding section.

\subsubsection{Size markers}

Table 7: Size markers

\begin{tabular}{ll}
\hline Size marker & Company \\
\hline PageRuler Prestained Protein Ladder & Thermo Scientific
\end{tabular}

\subsubsection{Software}

\section{Table 8: Software}

\begin{tabular}{ll}
\hline Program & Company \\
\hline 3 D -Software Imaris Bitplane Version 7.40 & Bitplane \\
Adobe Illustrator & Adobe \\
Axiovision Rel 4.7 & Zeiss \\
FACS DIVA software & BD Bioscience
\end{tabular}


LAS2000 Imaging System

Multi Gauge V3.2

Metamorph 6.3r2

Microsoft Office 2007

SAS software
Fujifilm

Fujifilm

Molecular Devices

Microsoft

SAS Institute

\subsubsection{Commercial kits}

Table 9: Commercial kits

\begin{tabular}{lll}
\hline Commercial kit & Application & Company \\
\hline PKH-linker kit & fluorescent cell labeling & Sigma-Aldrich \\
murine ELISA kits: IFN $\gamma$, IL-6, IL-10, & chemokines measurement & BioLegend \\
IL-12 p70 & &
\end{tabular}

\subsubsection{Buffers and solutions}

Digest buffer $(50 \mathrm{ml})$

$\begin{array}{rl}0.5 \mathrm{ml} & \begin{array}{l}1 \mathrm{M} \mathrm{2} \text { 2-(4-(2-hydroxyethyl)-1-piperazineethanesulfonic } \\ \text { acid }\end{array} \\ 5 \mathrm{ml} & 1.5 \mathrm{M} \mathrm{NaCl} \\ 0.5 \mathrm{ml} & 500 \mathrm{mM} \mathrm{KCl} \\ 0.5 \mathrm{ml} & 100 \mathrm{mM} \mathrm{MgCl}_{2} \\ 0.5 \mathrm{ml} & 200 \mathrm{mM} \mathrm{Ca} \mathrm{Cl} \\ \text { ad } 50 \mathrm{ml} & \text { aqua } \\ 0.25 \mathrm{ml} & 1 \% \mathrm{DNAse} \\ 0.25 \mathrm{ml} & 10 \mathrm{mg} / \mathrm{ml} \text { collagenase D }\end{array}$

ECL $1(10 \mathrm{ml})$

$\begin{array}{rl}1 \mathrm{ml} & 1 \mathrm{M} \text { Tris-HCl pH } 8.5 \\ 9 \mathrm{ml} & \text { aqua } \\ 45 \mu \mathrm{l} & 90 \mathrm{mM} \text { coumaric acid } \\ 100 \mu \mathrm{l} & 250 \mathrm{mM} \text { luminol }\end{array}$

ECL $2(10 \mathrm{ml})$

$\begin{array}{rl}1 \mathrm{ml} & 1 \mathrm{M} \text { Tris-HCl } \mathrm{pH} 8.5 \\ 9 \mathrm{ml} & \text { aqua } \\ 6 \mu \mathrm{l} & 30 \% \text { hydrogen peroxide }\end{array}$

Erythrocyte lysis buffer 10x (1 l)

$\begin{array}{rl}80.2 \mathrm{~g} & \mathrm{NH}_{4} \mathrm{Cl} \\ 8.4 \mathrm{~g} & \mathrm{NaHCO}_{3} \\ 20 \mathrm{ml} & 0.5 \mathrm{M} \mathrm{EDTA} \mathrm{pH} \mathrm{8,0} \\ \text { ad } 11 & \text { aqua }\end{array}$


MACS buffer $(500 \mathrm{ml})$

$\begin{array}{rl}495.5 \mathrm{ml} & \text { PBS } \\ 2.5 \mathrm{ml} & \text { FCS } \\ 2 \mathrm{ml} & 0.5 \mathrm{M} \text { EDTA } \mathrm{pH} 8.0\end{array}$

PBS 10x (5 l)

$\begin{array}{rll}400 \mathrm{~g} & \mathrm{NaCl} \\ 10 \mathrm{~g} & \mathrm{KCl} \\ 72 \mathrm{~g} & \mathrm{Na}_{2} \mathrm{HPO}_{4} \times 2 \mathrm{H}_{2} \mathrm{O} \\ 10 \mathrm{~g} & \mathrm{KH}_{2} \mathrm{PO}_{4} \\ \text { ad } 5 \mathrm{l} & \text { aqua }\end{array}$

adjust $\mathrm{pH}$ to 7.2

Ponceau-S staining solution $(50 \mathrm{ml})$

$\begin{aligned} 50 \mathrm{mg} & \text { Ponceau-S } \\ 2.5 \mathrm{ml} & \text { acetic acid } \\ \text { ad } 50 \mathrm{ml} & \text { aqua }\end{aligned}$

Protein lysis buffer $(20 \mathrm{ml})$

$\begin{array}{rl}200 \mu \mathrm{l} & 1 \mathrm{M} \text { Tris- } \mathrm{HCl} \mathrm{pH} \mathrm{7,0} \\ 1 \mathrm{ml} & 3 \mathrm{M} \text { sodium chloride } \\ 100 \mu \mathrm{l} & \mathrm{NP} 40 \\ \text { ad } 20 \mathrm{ml} & \text { aqua } \\ 1 \mathrm{x} & \text { protease inhibitor cocktail }\end{array}$

Running buffer 10x (2 l)

$288 \mathrm{~g}$ glycine

$60 \mathrm{~g}$ tris

$100 \mathrm{ml} \quad 10 \%$ SDS solution

ad 21 aqua

Substrate buffer $(11 \mathrm{ml})$

$10,89 \mathrm{ml} 200 \mathrm{mM}$ citric acid monohydrate

$110 \mu \mathrm{l} \quad 30 \%$ hydrogen peroxide

$5,1 \mu \mathrm{l}$ tetramethylbenzidine (TMB)

TBS-T (1 l)

$\begin{array}{rl}10 \mathrm{ml} & 1 \mathrm{M} \text { TRIS/HCl } \mathrm{pH} 7,0 \\ 2 \mathrm{ml} & 0.5 \mathrm{M} \text { EDTA pH } 8 \\ 50 \mathrm{ml} & \mathrm{NaCl} \\ 500 \mu \mathrm{l} & \text { Tween } 20(\mathrm{~T}) \\ \text { ad } 11 & \text { aqua }\end{array}$


Transfer buffer (1 l)

$\begin{array}{rl}2.93 \mathrm{~g} & \text { glycine } \\ 5.82 \mathrm{~g} & \text { tris } \\ 3.75 \mathrm{ml} & 10 \% \text { SDS solution } \\ 200 \mathrm{ml} & \text { methanol } \\ \text { ad } 11 & \text { aqua }\end{array}$

\subsubsection{Cell culture reagents and media}

Table 10: Cell culture reagents and media

\begin{tabular}{|c|c|}
\hline Reagents & Company \\
\hline$\beta$-mercaptoethanol & Sigma-Aldrich \\
\hline FCS (fetal calf serum) & PAA \\
\hline Hank's balanced salt solution (HBSS) without phenol red & Life technologies \\
\hline $\begin{array}{l}\text { 2-(4-(2-hydroxyethyl)-1-piperazineethanesulfonic acid } \\
\text { (HEPES) }\end{array}$ & PAA \\
\hline GM-CSF & $\mathrm{Lab}$ \\
\hline L-glutamine & Invitrogen \\
\hline non-essential amino acid & Invitrogen \\
\hline PBS (phosphate buffered saline) & PAA \\
\hline PCT Epidermal Keratinocyte Medium, CnT-07 & CellnTec \\
\hline Penicillin/ streptomycin (100x) & Invitrogen \\
\hline RMPI 1640 with L-glutamine & Invitrogen \\
\hline \multicolumn{2}{|l|}{ BMDC culture medium $(500 \mathrm{ml})$} \\
\hline \multicolumn{2}{|c|}{$440 \mathrm{ml}$ RMPI 1640 with L-glutamine } \\
\hline \multicolumn{2}{|c|}{$50 \mathrm{mM} \beta$-mercaptoethanol } \\
\hline \multicolumn{2}{|c|}{$50 \mathrm{ml}$ fetal calf serum (FCS) } \\
\hline \multicolumn{2}{|c|}{$5 \mathrm{ml} 200 \mathrm{mM}$ L-glutamine } \\
\hline \multicolumn{2}{|c|}{$5 \mathrm{ml} 100 \mathrm{U}$ penicillin $+100 \mu \mathrm{g} / \mathrm{ml}$ streptomycin } \\
\hline
\end{tabular}

T cell culture medium $(500 \mathrm{ml})$

$\begin{array}{ll}476 \mathrm{ml} & \text { BMDC culture medium } \\ 12.5 \mathrm{ml} & \begin{array}{l}1 \mathrm{M} \text { 2-(4-(2-hydroxyethyl)-1-piperazineethanesulfonic } \\ \text { acid }\end{array} \\ 5.6 \mathrm{ml} & 100 \mathrm{mM} \text { non-essential amino acid (Invitrogen) } \\ 5.6 \mathrm{ml} & 10 \mathrm{mM} \text { sodium pyruvate (Invitrogen) }\end{array}$

MPEK culture medium $(500 \mathrm{ml})$

$500 \mathrm{ml}$ PCT Epidermal Keratinocyte Medium, CnT-07

1x supplement A

1x supplement B

1x supplement C 


\subsubsection{Animals}

Table 11: Animals

\begin{tabular}{ll}
\hline Mouse & Company \\
\hline C57BL/6 & Charles River Laboratories \\
OT-I & Jackson Laboratory \\
OT-II & Jackson Laboratory
\end{tabular}

\subsubsection{Long-term culture cells}

Table 12: Long-term culture cells

\begin{tabular}{ll}
\hline Cell line & Company \\
\hline murine epidermal keratinocyte progenitor cell line MPEK-BL6 & CellnTec
\end{tabular}

\subsection{Methods}

\subsubsection{Animals}

Primary cells were isolated from C57BL/6, OT-I, or OT-II mice, respectively. Experiments were conducted according to the guidelines of the respective authority (LAVES, Niedersächsisches Landesamt für Verbraucherschutz und Lebensmittelsicherheit). Mice were raised in the animal facility of the University Medical Center Göttingen under high hygienic levels, $12 \mathrm{~h} / 12 \mathrm{~h}$ day/night cycle, and according to the natural needs of the species with food and water ad libitum.

\subsubsection{Cell culture (primary and long term)}

Cells were cultured under sterile conditions at $37^{\circ} \mathrm{C}, 5 \% \mathrm{CO}_{2}$, and $95 \%$ humidity. For long-term culture, the murine keratinocyte cell line MPEK-BL6 was used. As primary cells bone marrow-derived dendritic cells and CD4- and CD8-positive $\mathrm{T}$ cells were isolated. 


\subsubsection{Bone marrow-derived dendritic cells (BMDC)}

Generation of BMDC was accomplished as described previously (Braun et al. 2010; Lutz et al. 1999). On day 0, bone marrow of tibia and femur from C57B1/6 mice was rinsed out and cell suspension was collected. Erythrocytes were removed using erythrocyte lysis buffer for $7 \mathrm{~min}$ at room temperature. The remaining cells were washed twice with medium and counted with the help of a Neubauer counting chamber using trypan blue exclusion to determine cell viability. $2 \times 10^{6}$ of gained cells were sewed per tissue culture dish with $10 \mathrm{ml}$ of BMDC culture medium in the presence of $10 \%$ ( $\mathrm{vol} / \mathrm{vol})$ murine granulocyte macrophage colony-stimulating factor (GM-CSF)-containing supernatant. GM-CSF derived from a murine GM-CSF clone (hypoxanthine-aminopterin-thymidine-sensitive Ag8653 myeloma cell line transfected with murine GM-CSF cDNA isolated from a $\mathrm{T}$ cell clone by PCR and inserted into the vector BCMGSNeo) (Zal et al. 1994). On day 3 and 6, culture medium and GM-CSF were additionally added or used for replacement, respectively, to a total volume of $20 \mathrm{ml}$ culture medium containing $10 \%$ ( $\mathrm{vol} / \mathrm{vol}$ ) GM-CSF. On day 8, generation of BMDC was completed and non-adherent and loosely adherent cells, corresponding to the generated population of BMDC, were harvested and subjected to further experiments. Generated BMDC were considered as semi-mature.

\subsubsection{Purification of CD4- and CD8-positive T cells}

To assess the antigen-specific immunostimulatory potential of exosomes, CD4- and CD8-positive $\mathrm{T}$ cells from transgenic mice (OT-I and OT-II, respectively), expressing an OVA specific $\mathrm{T}$ cell receptor, were used. For $\mathrm{T}$ cell purification, spleen and axial, brachial, and inguinal lymph nodes were mechanically and chemically prepared. Shortly, spleen cells were passed through a $70 \mu \mathrm{m}$ cell strainer, the cell suspension was depleted of erythrocytes using erythrocyte lysis buffer for $7 \mathrm{~min}$ at room temperature, and cells were washed in MACS buffer. Lymph nodes were chemical digested with digest buffer for $30 \mathrm{~min}$ at $37^{\circ} \mathrm{C}$. Afterwards, cells were washed and CD4- and CD8-positive T cells of spleen and 
lymph nodes were enriched using specific antibody-coated magnetic microbeads. The principle used was based on positive magnetic sorting (MACS). Desired cell population was labeled with magnetic antibodies. For labeling $90 \mu 1$ of MACS buffer per $10^{7}$ cells were incubated with $10 \mu$ l either CD4-or CD8a-specific micro beads per $10^{7}$ cells for $15 \mathrm{~min}$ at $4{ }^{\circ} \mathrm{C}$ in the dark. Suspension was washed with $1 \mathrm{ml}$ MACS buffer per $10^{7}$ cells. Cells were pelleted and collected in $1 \mathrm{ml}$ of degassed MACS buffer. A separation column was attached to a magnet and rinsed with $1 \mathrm{ml}$ of degassed MACS buffer. Afterwards, cell suspension was given through the column and the magnetic labeled cells were caught within the column whereas all other cells were rinsed out with $9 \mathrm{ml}$ of MACS buffer and collected as negative population. Removal of the column from the magnet and rinsing of the column freed positive cells. CD4- and CD-8 positive T cells, respectively, were counted with the aid of a Neubauer counting chamber using trypan blue dye to determine cell viability.

\subsubsection{Long term culture}

The murine epidermal keratinocyte progenitor cell line MPEK-BL6 was cultivated in serum-free keratinocyte medium. Cells were cultivated in $175 \mathrm{~cm}^{2}$ culture flasks and passaged when a confluence of $80-90 \%$ was reached to avoid differentiation of cells. For harvesting MPEK were washed with PBS and incubated with $5 \mathrm{ml}$ $0.05 \% / 0.02 \%$ trypsin-EDTA for $19 \mathrm{~min}$ at $37^{\circ} \mathrm{C}$. To end the reaction, $5 \mathrm{ml}$ $1 \%$ trypsin-inhibitor were added. MPEK were washed, pelleted and counted using a Neubauer counting chamber and trypan blue exclusion to determine cell viability. Keratinocytes were seeded at a density of $4.6-8.6 \times 10^{3}$ cells $/ \mathrm{cm}^{2}$ depending on the following experiments.

To demonstrate antigen uptake by MPEK, the model antigen OVA was used. Cells were incubated for $24 \mathrm{~h}$ with $10 \mu \mathrm{g} / \mathrm{ml}$ or $20 \mu \mathrm{g} / \mathrm{ml}$ of FITC labeled OVA. To distinguish between nonspecific attachment and active antigen uptake, cells were either incubated at $4{ }^{\circ} \mathrm{C}$ or at $37^{\circ} \mathrm{C}$, respectively. Analysis of fluorescence intensity was conducted by flow cytometry and immunofluorescence. 
For exosome purification, MPEK were seeded at a density of $4.6 \times 10^{3}$ cells $/ \mathrm{cm}^{2}$ and cultured for a total of $96 \mathrm{~h}$. Within the first $48 \mathrm{~h}$, cells were incubated with or without $1 \mathrm{mg} / \mathrm{ml} \mathrm{OVA.} \mathrm{To} \mathrm{remove} \mathrm{residual} \mathrm{OVA} \mathrm{from} \mathrm{the} \mathrm{supernatant,} \mathrm{cells} \mathrm{were}$ then washed extensively with PBS. Thereafter, cells were stimulated for $48 \mathrm{~h}$ with or without $50 \mathrm{ng} / \mathrm{ml} \mathrm{IFN \gamma}$, or with $10 \mathrm{ng} / \mathrm{ml} \mathrm{IL-4} \mathrm{and} 50 \mathrm{ng} / \mathrm{ml} \mathrm{IL-13,} \mathrm{or} \mathrm{with}$ $10 \mathrm{ng} / \mathrm{ml} \mathrm{IL-17,} 50 \mathrm{ng} / \mathrm{ml}$ IL-22, and $25 \mathrm{ng} / \mathrm{ml} \mathrm{TNF} \alpha$. Afterwards, supernatant of MPEK was collected to purify exosomes, and MPEK were lysed for Western blot analysis. The different steps of incubation and stimulation described led to six different conditions as summarized in table 13. Differently generated exosomes were used for analysis and functional experiments.

Table 13: Conditions for exosome generation

\begin{tabular}{ll}
\hline $\mathbf{0 - 2 4} \mathbf{h}$ & $\mathbf{2 4 - 4 8} \mathbf{~ h}$ \\
\hline+ medium & + medium \\
+ medium & + IFN $\gamma$ \\
+ OVA & + medium \\
+ OVA & + IFN $\gamma$ \\
+ medium & + IL-4 IL-13 \\
+ medium & + IL-17, IL-22, TNF $\alpha$
\end{tabular}

\subsubsection{Exosome purification}

To purify exosomes, cell culture supernatant of MPEK, raised under different conditions as described above, was collected. To remove remaining cells, supernatant was centrifuged at 2,000 x g. To eliminate cell debris, the supernatant was transferred to ultracentrifugation tubes and centrifuged at $10,000 \mathrm{xg}$. To remove further impurities, the supernatant was filtrated through a $0.2 \mu \mathrm{m}$ pore filter and exosomes were pelleted at 100,000 x g for $2.5 \mathrm{~h}$. The invisible pellet was either collected in $50 \mu \mathrm{l}$ PBS per tube for the following experiments or lysed with NP40 containing lysis buffer for Western blot analysis. All ultracentrifugation steps were carried out at $4^{\circ} \mathrm{C}$. 


\subsubsection{Density analysis of MPEK-derived membrane vesicles}

To assess whether MPEK-derived membrane vesicles had a compatible density for exosomes, vesicles were layered on a continuous sucrose gradient. This method allows to separate membrane vesicles according to their density (Thery et al. 2006). The used gradient consisted of eight fractions carefully overlaid with 2.5-0.5 M sucrose in $20 \mathrm{mM}$ HEPES. Membrane vesicles pelleted at $100,000 \mathrm{xg}$ were collected in PBS and added upon the lightest fraction. Gradients were centrifuged for $15 \mathrm{~h}$ at $100,000 \mathrm{x} \mathrm{g}$ using a swinging bucket rotor. Thereafter, each fraction was diluted 1:8 in PBS and centrifuged again at 100,000 x g for $1 \mathrm{~h}$. Pelleted membrane vesicles were collected in NP40 containing lysis buffer and subjected to Western blot analysis.

\subsubsection{Fluorescence labeling of exosomes}

To visualize aggregates of exosomes in fluorescence microscopy, exosomes were stained with lipophilic dye using a commercial linker kit for general membrane labeling. $100 \mu \mathrm{l}$ of the exosome suspension were diluted in $900 \mu \mathrm{l}$ Diluent $\mathrm{C}$ and mixed carefully. $1 \mu \mathrm{M}$ PKH26 was added and exosomes were incubated for $5 \mathrm{~min}$ at room temperature. The reaction was stopped using $200 \mu \mathrm{l}$ of exosome-free FCS. Afterwards, exosomal suspensions were pooled and diluted 1:6 in PBS to clear exosomes from redundant dye to avoid unspecific overspill. Exosomes were pelleted at $100,000 \mathrm{xg}$ for $1 \mathrm{~h}$.

\subsubsection{Functional experiments}

\subsubsection{Co-culture of BMDC and exosomes}

Generated BMDC were harvested on day 8 and extensively washed with culture medium containing exosome-depleted FCS. $2 \times 10^{6}$ cells per well of a six well culture dish were incubated in $2 \mathrm{ml}$ exosome-depleted medium with $10 \mu \mathrm{g} / \mathrm{ml}$ MPEK-derived exosomes. BMDC were incubated with PKH26-labeled exosomes 
to visualize exosome-uptake in a time series using immunofluorescence microscopy and flow cytometry. Cells were harvested after $0.5 \mathrm{~h}, 4 \mathrm{~h}$, and $24 \mathrm{~h}$.

For analysis of exosomes' impact on BMDC phenotype and interleukin profile, cells were incubated for $24 \mathrm{~h}$ with $10 \mu \mathrm{g} / \mathrm{ml}$ of non-labeled exosomes. Thereafter, BMDC were subjected to flow cytometry for phenotype analysis, and supernatant was collected for ELISA-based measurement of interleukin production. To determine if exosomes generated under various conditions differ regarding their impact on BMDC, the effect of different kinds of exosomes (Exo +/- OVA +/- IFN $\gamma$ ) on BMDC was analyzed. OVA-incubated $(100 \mu \mathrm{g} / \mathrm{ml})$ and medium only incubated BMDC served as controls.

\subsubsection{T cell proliferation assay}

For proliferation assays, CD4- or CD8-positive T cells were labeled with CFDA-SE. Intracellular; CFDA-SE is converted to the fluorophore CFSE. As CFSE binds to intracellular molecules and is present within the cytoplasm, every cell division will halve CFSE fluorescence intensity. T cells were incubated in 2.5 $\mu \mathrm{M}$ CFSE in PBS for $8 \mathrm{~min}$ at $37^{\circ} \mathrm{C}$ in the dark, followed by two washing steps with $\mathrm{T}$ cell medium to remove residual dye. $1 \times 10^{5} \mathrm{~T}$ cells in $200 \mu 1$ medium were co-cultured in 96-well plates with either exosomes $(10 \mu \mathrm{g} / \mathrm{ml})$ or with exosome-pretreated BMDC in different $\mathrm{T}$ cell:BMDC ratios of 3:1, 10:1, or 30:1. Culture medium was used with or without IL-2 $(10 \mathrm{ng} / \mathrm{ml})$ as additional survival factor. Medium-incubated T cells and medium-incubated BMDC served as negative controls. T cells stimulated with CD3e- and CD28-directed antibodies $(1 \mu \mathrm{g} / \mathrm{ml}$, respectively) and OVA-pretreated BMDC served as positive controls. After $72 \mathrm{~h}$ of co-incubation, cells were collected and measured by flow cytometry for CFSE intensity and supernatant was assessed by ELISA for IFN $\gamma$ production. 


\subsubsection{ELISA}

Cytokine production was quantified by a sandwich ELISA. Cell culture supernatant of BMDC or T cells was collected and measured for murine IL-6, IL-10, IL-12p70, or IFN $\gamma$, respectively, as recommended by the manufacturer. Briefly, on the first day 96-well plates were coated with $100 \mu 1 /$ well capture antibody dissolved in either coating buffer $\mathrm{A}$ as provided within the kit or with regard to IL-10 in $200 \mathrm{mM}$ sodium dihydrogen phosphate. Plates were sealed and incubated at $4^{\circ} \mathrm{C}$ over night. After plates had been washed in $0.005 \%$ Tween in PBS, wells were incubated for $2 \mathrm{~h}$ at room temperature with $200 \mu \mathrm{l} /$ well blocking buffer to prevent unspecific bindings. After three washing steps in $0.005 \%$ Tween in PBS, triplets of $100 \mu \mathrm{l}$ per sample were loaded onto the different wells. Dilution of samples had been determined experimentally. Standard proteins as references to extrapolate concentration of chemokines were used as described by the company. After $2 \mathrm{~h}$ of incubation and three following washing steps in $0.005 \%$ Tween in PBS, plates were incubated for $1 \mathrm{~h}$ with $100 \mu \mathrm{l} /$ well of detection antibody. Afterwards, plates were washed again as described above and avidin-horseradish peroxidase (HRP) was given to the samples for $30 \mathrm{~min}$ followed by five washing steps in $0.005 \%$ Tween in PBS. Subsequent $100 \mu 1 /$ well substrate buffer were added. Incubation was carried out in the dark, the duration depended onto the chemokines and lasted between $5 \mathrm{~min}$ (IL-6) and $15 \mathrm{~min}$ (IL-10). To end the reaction, $2 \mathrm{M}$ sulfuric acid was added. The color change was measured at $450 \mathrm{~nm}$ in an Appliskan micro plate reader. To assure equal distribution of different solutions, plates were put onto a shaker during incubation.

\subsubsection{Flow cytometry}

Flow cytometry allows differentiation between cells due to their refraction of light. Additionally, cells can be labeled with fluorescence-coupled antibodies to analyze expression of proteins. Cells were harvested, washed in PBS, and pipetted into the tubes. 500,000 BMDC or MPEK and 100,000 T cells, respectively, were used per tube. To exclude unspecific binding, cells were washed in PBS and incubated with 
$10 \mu \mathrm{l}$ anti-CD16/CD32 per sample for $10 \mathrm{~min}$ at $4{ }^{\circ} \mathrm{C}$. Thereafter, cells were stained with $10 \mu \mathrm{l}$ of the desired antibody or the corresponding isotype control for $30 \mathrm{~min}$ at $4{ }^{\circ} \mathrm{C}$ (for concentrations compare tab. 14), followed by another washing step. Immediately prior to measurement, $10 \mu \mathrm{l}$ of $50 \mu \mathrm{g} / \mathrm{ml}$ propidium iodide (PI) were added to each sample to determine cell viability. Cells were analyzed with a FACS Canto II and the FACS DIVA software. Analysis of MPEK in flow cytometry could be accomplished without previous staining since OVA was directly labeled with FITC. In this case only additional staining with PI was accomplished. Phenotypic characterization of BMDC surface markers was performed on day nine with the following antibodies: CD11c, CD40, CD86, MHC I, and MHC II. When uptake of exosomes was analyzed, all markers except MHC I were measured. The phycoerythrin (PE) filter was suitable for PKH26 measurement for PKH-labeled exosomes. Analysis of T cells after co-culture with BMDC was conducted with antibodies directed against the following antigens: CD11c and CD4 or CD8a.

Table 14: Antibodies used in FACS

\begin{tabular}{llcl}
\hline Antibody & Clone & Concentration used & Fluorophore \\
\hline CD4 & GK1.5 & $2 \mu \mathrm{g} / \mathrm{ml}$ & PE/Cy7 \\
CD8a & $53-6.7$ & $2 \mu \mathrm{g} / \mathrm{ml}$ & PE/Cy7 \\
CD11c & N418 & $2 \mu \mathrm{g} / \mathrm{ml}$ & APC/Cy7 \\
CD16/CD32 & $2.4 \mathrm{G} 2$ & $5 \mu \mathrm{g} / \mathrm{ml}$ & purified \\
CD40 & $3 / 23$ & $4 \mu \mathrm{g} / \mathrm{ml}$ & APC \\
CD86 & GL-1 & $1 \mu \mathrm{g} / \mathrm{ml}$ & PE/Cy7 \\
MHC I (H-2K $\left.{ }^{\mathrm{b}}\right)$ & AF6-88.5 & $2 \mu \mathrm{g} / \mathrm{ml}$ & PE \\
MHC II (I-A/I-E) & M5/114.152 & $5 \mu \mathrm{g} / \mathrm{ml}$ & FITC
\end{tabular}

With regard to all experiments, corresponding isotype controls were purchased from the same manufacturer and handled in the same manner as the specific antibodies (all BioLegend with the exception of anti-CD16/CD32 being purchased from BD Bioscience). 


\subsubsection{Microscopy}

\subsubsection{Fluorescence microscopy}

For fluorescence microscopy analysis, MPEK were plated onto chamber slides and cultivated for $48 \mathrm{~h}$ followed by $24 \mathrm{~h}$ of incubation with $20 \mu \mathrm{g} / \mathrm{ml}$ FITC-labeled OVA. Incubation was carried out at different temperatures to differentiate between unspecific binding at $4{ }^{\circ} \mathrm{C}$ and active antigen uptake at $37^{\circ} \mathrm{C}$. Following, cells were extensively washed in PBS and fixed with ice-cold methanol for $10 \mathrm{~min}$. BMDC, incubated with $10 \mu \mathrm{g} / \mathrm{ml}$ PKH-labeld exosomes for $24 \mathrm{~h}$, were harvested, washed and prepared as cytospin preparation with a density of 50,000 cells/slide. Briefly, $100 \mu \mathrm{l}$ of BMDC $(500,000$ cells $/ \mathrm{ml})$ were added per sample and centrifuged in cytospin for $10 \mathrm{~min}$ at $800 \mathrm{rpm}$. Dried slides were fixed in ice-cold methanol and let dry again. BMDC as well as MPEK were covered with Fluorescence Mounting Medium supplemented with $0.5 \mu \mathrm{g} / \mathrm{ml}$ DAPI for nuclear staining. An Axiovert $40 \mathrm{C}$ microscope and AxioVision 4.7 software were used for image acquisition.

\subsubsection{Confocal microscopy}

To confirm OVA uptake by MPEK, confocal images were acquired. MPEK were cultivated in chamber slides and incubated with medium or purified OVA $\left(1 \mathrm{mg} / \mathrm{ml}\right.$ ) for $24 \mathrm{~h}$. For membrane labeling, cells were incubated for $10 \mathrm{~min}$ at $37^{\circ} \mathrm{C}$ with $300 \mu \mathrm{l} /$ chamber of $3.3 \mu \mathrm{g} / \mathrm{ml}$ wheat germ agglutinin (WGA) Alexa Fluor 633 conjugate in HBSS. WGA labels membranes by selective binding to $\mathrm{N}$-acetylglucosamine and $\mathrm{N}$-acetylneuraminic acid residues (Wright 1984). After five washing steps with HBSS, keratinocytes were fixed in 4\% PFA for $15 \mathrm{~min}$ at $4^{\circ} \mathrm{C}$ and were washed again in HBSS. To prevent antibodies from unspecific binding, samples were incubated with 5\% FCS in PBS for $1 \mathrm{~h}$. To facilitate penetration of antibodies through cell membranes, the blocking solution also contained $0.2 \%$ of Triton $X$ to increase permeability. Anti-ovalbumin in $2.5 \%$ FCS served as primary antibody. Incubation was carried out overnight at $4^{\circ} \mathrm{C}$. Afterwards, samples were extensively washed with PBS over $30 \mathrm{~min}$ before 
incubation with secondary antibody in $2.5 \%$ FCS was conducted for $1 \mathrm{~h}$ at room temperature, followed by multiple washing steps in PBS. Samples were covered with Fluorescence Mounting Medium supplemented with $0.5 \mu \mathrm{g} / \mathrm{ml}$ DAPI for nuclear staining. Analysis was carried out with an Olympus Fluoview 1000 and the help of Dr. J. Wessels and J. Mahrt (MOLCI (Molecular and Live Cell Imaging service facility), University Medical Center Göttingen).

Table 15: Antibodies used in confocal microscopy

\begin{tabular}{llcll}
\hline Antibody/ Lectin & Host & Concentration used & Fluorophore & Manufacturer \\
\hline ovalbumin & mouse & $1 \mu \mathrm{g} / \mathrm{ml}$ & purified & Biozol \\
mouse & goat & $2.5 \mu \mathrm{g} / \mathrm{ml}$ & Alexa Fluor 488 & Cell Signaling \\
WGA & -- & $3.3 \mu \mathrm{g} / \mathrm{ml}$ & Alexa Fluor 633 & Invitrogen
\end{tabular}

\subsubsection{Electron microscopy}

Due to the size of exosomes of 50-100 nm (Thery et al. 2009), electron microscopy is necessary to visualize the vesicles. For analysis, the drop-to-drop method was used. Briefly, a carbon-coated 400-mesh copper grid was positioned on a drop of a liquid specimen to absorb for $1 \mathrm{~min}$; excess fluid was carefully removed with filter paper. Following, the grid was placed within a large drop of $1 \%$ glutaraldehyde to absorb for $1 \mathrm{~min}$, and excess fluid was once again removed. After washing in 5 drops of $\mathrm{dH}_{2} \mathrm{O}$, staining with $1 \%$ uranyl acetate for $30 \mathrm{sec}$ was performed. The dried grid was examined with a CM120 electron microscope and images were recorded using an iTEM-Camera. D. Wenzel, Electron Microscopy Group, Max Planck Institute for Biophysical Chemistry, Göttingen, carried out preparation of samples and microscopy.

\subsubsection{Protein analysis}

\subsubsection{Bradford assay}

Proteins were quantified using Bradford assays. Coomassie Brilliant Blue binds to the present protein in the particular sample, the formed protein complex leads to a 
change of the absorption maximum from $465 \mathrm{~nm}$ to $595 \mathrm{~nm}$ that can be measured photometrically. Before analysis, samples were prepared as follows: MPEK and spleen cells, purified as described in "Purification of CD4- and CD8-positive T cells" (page 19), were lysed with the appropriate amount of lysis buffer, mechanically homogenized, and lysates were centrifuged. The supernatant was analyzed further and the pellet was discarded. Exosomes resuspended in lysis buffer were subjected to Bradford assays. One blank and six samples with defined protein amounts were used to generate a standard concentration graph. Samples were prepared as follows:

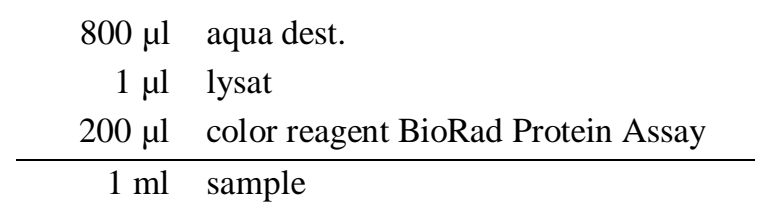

Samples were vortexed and measurement was accomplished with a spectrometer at $595 \mathrm{~nm}$ within $5 \mathrm{~min}$ to $1 \mathrm{~h}$ due to samples' stability in that time period.

\subsubsection{SDS-Page and Western blot}

Before samples were loaded onto a $10 \%$ acrylamide gel and subjected to SDS-PAGE analysis, 5x SDS sample buffer and 1 M DTT were added with final concentrations of $1 \mathrm{x}$ and $50 \mathrm{mM}$, respectively. Equal protein amounts were loaded onto the gel.

\section{1x stacking gel}

$1.55 \mathrm{ml}$ aqua bidest.

$0.25 \mathrm{ml} \quad 30 \%$ acrylamide mix

$0.19 \mathrm{ml} \quad 1 \mathrm{M}$ Tris $\mathrm{HCl} \mathrm{pH} 6.8$

$15 \mu 1 \quad 10 \%$ SDS

$15 \mu \mathrm{l} \quad 10 \%$ APS

$1.5 \mu 1 \quad$ TEMED 1x separation gel $10 \%$

$\begin{array}{rl}2 \mathrm{ml} & \text { aqua bidest. } \\ 1.65 \mathrm{ml} & 30 \% \text { acrylamide mix } \\ 1.25 \mathrm{ml} & 1.5 \mathrm{M} \text { Tris HCl pH } 8.8 \\ 50 \mu \mathrm{l} & 10 \% \text { SDS } \\ 50 \mu \mathrm{l} & 10 \% \text { APS } \\ 7.5 \mu \mathrm{l} & \text { TEMED }\end{array}$

A prestained protein ladder $(5 \mu \mathrm{l})$ was used as size marker. Samples were separated at $200 \mathrm{~V}$ with the usage of $1 \mathrm{x}$ running buffer until the dye reached the lower boarder of the gel. Using the procedure of semi dry blot and transfer buffer for $40 \mathrm{~min}$ at $150 \mathrm{~mA}$, samples were transferred to a nitrocellulose membrane. 
Successful transfer of proteins was controlled by membrane staining with Ponceau-S. To prevent antibodies from unspecific binding, the membrane was blocked for $1 \mathrm{~h}$ at room temperature with 5\% non-fat-dry-milk (NFDM) in TBS-T. Afterwards, incubation with primary antibodies occurred overnight at $4{ }^{\circ} \mathrm{C}$. The following antibodies were dissolved in 1\% NFDM in TBS-T, with the exception of anti-alix, which was dissolved only in TBS-T:

Table 16: Primary antibodies used in Western blot analysis

\begin{tabular}{llcl}
\hline Antibody & Host species & Concentration used & Company \\
\hline actin & mouse & $0.3 \mu \mathrm{g} / \mathrm{ml}$ & Millipore \\
alix & mouse & $1 \mu \mathrm{g} / \mathrm{ml}$ & Biozol \\
calnexin & rabbit & $1 \mu \mathrm{g} / \mathrm{ml}$ & antibodies-online \\
flotillin & mouse & $50 \mathrm{ng} / \mathrm{ml}$ & BD Bioscience \\
lamin & rabbit & $0.5 \mu \mathrm{g} / \mathrm{ml}$ & Cell Signaling \\
MHC class I H2 Kb & rabbit & $5 \mu \mathrm{g} / \mathrm{ml}$ & Abcam \\
MHC II (I-A/I-E) & rat & $10 \mu \mathrm{g} / \mathrm{ml}$ & Millipore \\
ovalbumin & mouse & $0.2 \mu \mathrm{g} / \mathrm{ml}$ & Sigma-Aldrich
\end{tabular}

After three washing steps with TBS-T, membranes were incubated with HRP-coupled secondary antibodies in $0.83 \%$ NFDM in TBS-T for $1 \mathrm{~h}$ at room temperature. The following secondary antibodies were used:

Table 17: Secondary antibodies used in Western blot analysis

\begin{tabular}{llcl}
\hline Antibody & Host species & Concentration used & Company \\
\hline mouse & goat & $4 \mu \mathrm{g} / \mathrm{ml}$ & Promega \\
rabbit & goat & $4 \mu \mathrm{g} / \mathrm{ml}$ & Promega \\
rat & goat & $0.67 \mu \mathrm{g} / \mathrm{ml}$ & Linaris
\end{tabular}

After three washing steps as described above, membranes were incubated with ECL solution 1 and 2 in a ratio of 1:1. For signal detection, the LAS 2000 imaging system was used. To confirm equal protein loading, membranes were washed thrice in TBS-T, stripped using commercial stripping buffer, washed thrice again and incubation with primary antibodies (actin, lamin) was carried out as described above. 


\subsubsection{Proteomic analysis}

The content of MPEK-derived exosomes was assessed by proteomic analysis. Proteins of purified exosomes were separated by one-dimensional SDS-PAGE and the gel was stained with Coomassie Brilliant Blue. Slices of the cut gel were reduced with $10 \mathrm{mM}$ DTT, alkylated with $55 \mathrm{mM}$ IAA for $20 \mathrm{~min}$ at $26^{\circ} \mathrm{C}$, and digested with trypsin overnight at $37^{\circ} \mathrm{C}$ (Shevchenko et al. 1996). Tryptic peptides were injected onto a C18 pre-column to elute bound peptides. Thereafter, bound peptides were separated on a C18 capillary column using a nanoflow LC system coupled to an LTY-Orbitrap XL hybrid mass spectrometer using MS and MS/MS acquisition alternately. Raw data were analyzed with Mascot search engine against NCBI protein database for peptide and protein identifications. For annotation of acquired data, Scaffold (Proteome Software, Version 3.4) was applied with the following parameter settings: minimum peptide and protein identification probability $80 \%$ and minimum of 2 identified peptides per protein. As basis for analysis, every sample had to express the exosomal markers flotillin, alix, and tsg101. To be considered to be expressed at higher or lower levels, the respective protein had to be twice as much or half in comparison to medium control. Proteomic analysis was carried out by Prof. H. Urlaub, Bioanalytical Mass Spectrometry Group, Max Planck Institute for Biophysical Chemistry and Bioanalytics, Göttingen.

\subsubsection{Statistics}

Statistic data analysis was done using the rank-sum test with ANOVA-type statistics (Brunner et al. 2001). Data are visualized as means with error bars indicating standard deviation (SD), * indicates $\mathrm{p}<0.05$. 


\section{Results}

\subsection{The murine kerationcyte cell line MPEK produces exosomes}

To address the question whether murine keratinocytes are able to produce exosomes, the MPEK cell line was cultivated and analyzed using a modified standard protocol for exosome purification (Thery et al. 2006). Supernatant of MPEK that had been treated with or without IFN $\gamma$ (to imitate inflammatory conditions) was collected and after different centrifugation and filtration steps purified membrane vesicles of MPEK were obtained. Of interest, the quantity of produced exosomes by MPEK was comparable with and without IFN $\gamma$ stimulation (Appendix table 28). Exosomes were analyzed with regard to their main characteristics: their size of $50-100 \mathrm{~nm}$ and their saucer-like shape in electron microscopy, their expression of exosomal markers like alix and flotillin in Western blot and proteomic analysis (Thery et al. 2009), and their density of $1.10-1.21 \mathrm{~g} / \mathrm{ml}$ in sucrose gradients (Mathivanan et al. 2012). MPEK-derived membrane vesicles pictured in electron microscopy had a saucer-like shape and a diameter of 60-90 nm (Fig. 5a). The presence of the exosomal markers flotillin and alix and the absence of calnexin, a protein of the endoplasmic reticulum indicating contamination (Thery et al. 2006), were demonstrated by Western blot analysis (Fig. 5b). Moreover, these findings, as well as the presence of additional exosomal markers like tsg101 and CD81, were confirmed by proteomic analysis (Simpson et al. 2008) (Table 18). For further characterization, membrane vesicles were layered on a continuous sucrose gradient to determine the vesicle density. Analysis of the different density fractions by Western blot revealed the presence of flotillin at a density of $1.10 \mathrm{~g} / \mathrm{ml}$ (Fig. 5c), consistent with exosomal content. Thus, with regard to shape, size, density, and expression of exosomal markers, MPEK-derived membrane vesicles meet all required criteria and could be considered as exosomes. 
a

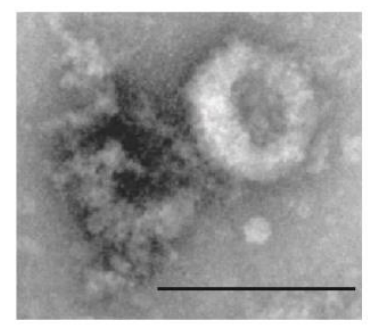

b

$\frac{\text { Exo }}{-\quad \text { IFNy }} \frac{\text { MPEK }}{- \text { IFNy }}$

\section{calnexin $85 \mathrm{kDa}$}

flotillin $42 \mathrm{kDa}$

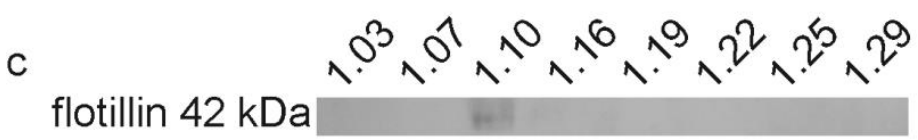

Figure 5: MPEK produce exosomes. Analysis of MPEK-derived membrane vesicles with regard to exosome-defining traits. (a) Purified vesicles were visualized by electron microscopy picturing their saucer-like shape and size between $60-90 \mathrm{~nm}$. Scale bar $=100 \mathrm{~nm}$. (b) The presence of the exosomal markers alix and flotillin as well as the absence of the negative marker calnexin was detected by Western blot. $30 \mu \mathrm{g}$ of lysate per sample were used for analysis of calnexin and flotillin and $40 \mu \mathrm{g}$ for analysis of alix. Flotillin also served as loading control for calnexin. (c) Density analysis of the purified vesicles by means of sucrose gradient revealed the presence of flotillin in the fraction of $1.10 \mathrm{~g} / \mathrm{ml}$, compatible with exosomal density.

Table 18: Exosomal markers detected by proteomic analysis

\begin{tabular}{lcccl}
\hline Protein name & Exosome & Exosome IFN $\boldsymbol{\gamma}$ & MW (kDa) & Accession no. \\
\hline alix & + & + & 96 & NP_001158150 \\
calnexin & -- & -- & & \\
CD80 & + & + & 35 & NP_033985 \\
CD81 & + & + & 18 & NP_598416 \\
flotillin-1 & + & + & 48 & NP_032053 \\
tsg101 & + & + & 44 & NP_068684
\end{tabular}




\subsection{MPEK internalize antigen and shuttle it to their exosomes}

To assess whether MPEK are able to take up antigen and transfer it to their exosomes, the model antigen ovalbumin (OVA) was used. Keratinocytes were incubated with fluorescence labeled OVA at $4{ }^{\circ} \mathrm{C}$ or $37^{\circ} \mathrm{C}$ to distinguish between unspecific binding and active antigen uptake, respectively. As demonstrated by fluorescence microscopy (Fig. 6a) and FACS analysis (Fig. 6b), MPEK incubated at $37^{\circ} \mathrm{C}$, unlike their counterparts incubated at $4^{\circ} \mathrm{C}$, showed a strong fluorescence signal indicating active internalization of antigen. To assure antigen uptake and localization within the cell, OVA incubated MPEK were also analyzed by confocal microscopy confirming previous findings (Fig. 6c).

Furthermore, uptake of pure OVA protein pictured by Western blot showed a doublet band at around $45 \mathrm{kDa}$ that was also present when OVA incubated MPEK were analyzed (Fig. 6d). As exosomes contain membrane and cytosolic proteins of their cell of origin (Simpson et al. 2008), OVA internalized by MPEK should be transferred to MPEK-derived exosomes. Confirming this hypothesis, exosomes purified from OVA incubated MPEK showed a single band at $45 \mathrm{kDa}$ in Western blot (Fig. 6e). When MPEK were stimulated with IFN $\gamma$ prior to exosome purification, the OVA signal in Western blot was enhanced (for quantification, in densitometric analysis enhancement was more than threefold), suggesting an increase of antigen uptake and transfer under inflammatory conditions. 
a
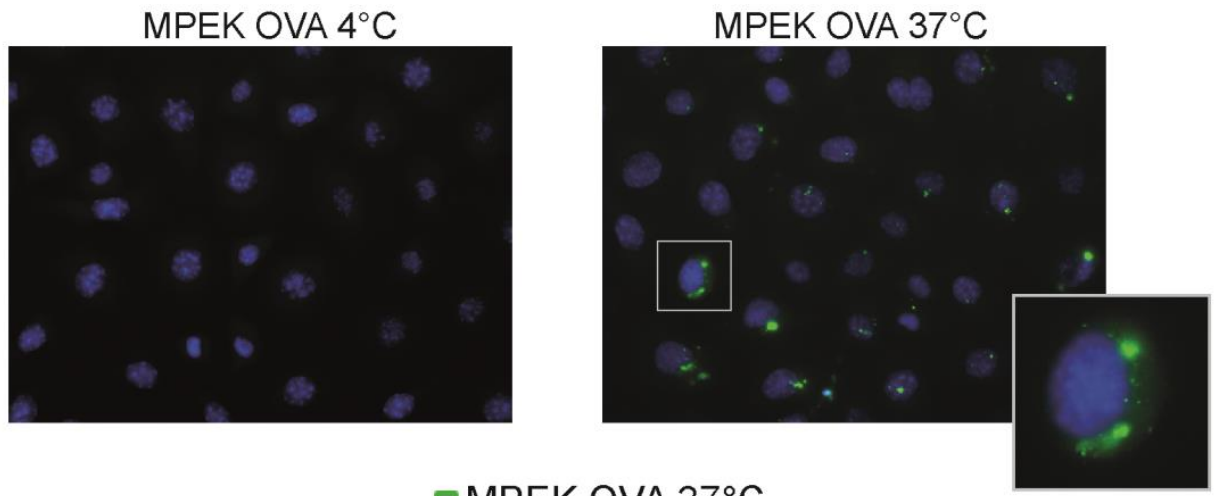

b

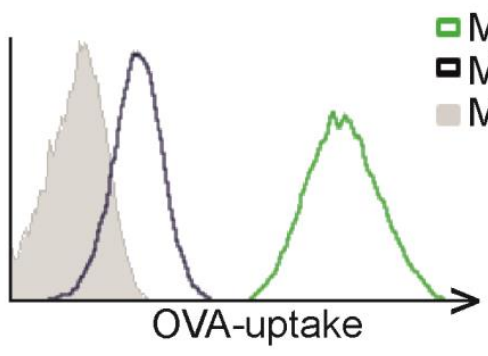

- MPEK OVA $37^{\circ} \mathrm{C}$

- MPEK OVA $4^{\circ} \mathrm{C}$

MPEK Medium

C

MPEK

MPEK OVA
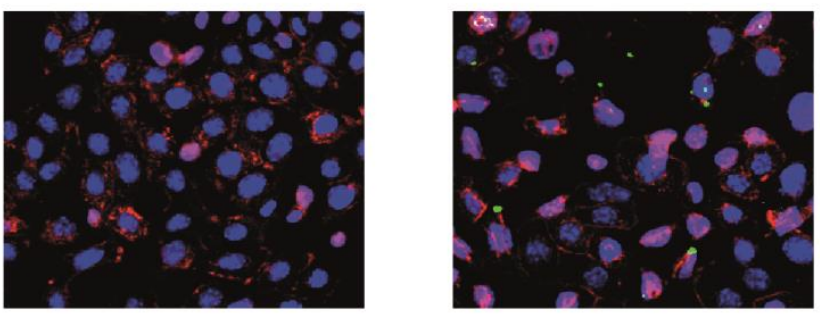

MPEK OVA

d

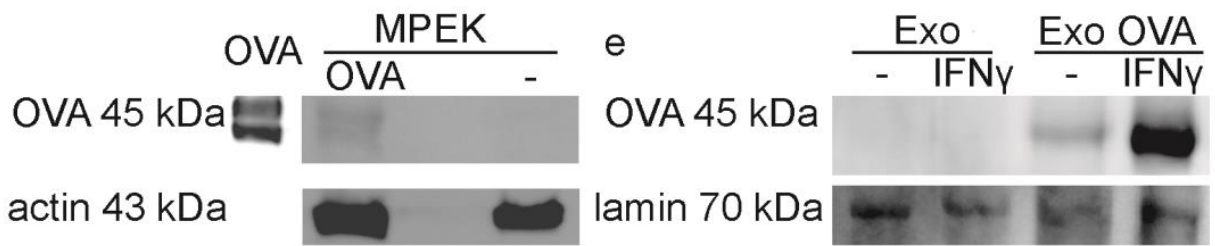

Figure 6: MPEK internalize OVA and shuttle it to their exosomes. To distinguish between active antigen uptake versus unspecific binding MPEK were incubated with FITC-labeled OVA (green) at $4^{\circ} \mathrm{C}$ and $37^{\circ} \mathrm{C}$ as pictured by (a) fluorescence microscopy and (b) flow cytometry, respectively. $20 \mu \mathrm{g} / \mathrm{ml}$ were used for analysis by fluorescence microscopy and $10 \mu \mathrm{g} / \mathrm{ml}$ for analysis by flow cytometry. In contrast to incubation at $4^{\circ} \mathrm{C}$, incubation at $37^{\circ} \mathrm{C}$ led to a strong increase of fluorescence intensity suggesting active antigen uptake. For flow cytometry, only viable cells were taken into consideration. (c) Findings were confirmed by confocal microscopy demonstrating the presence of antigen (green) in OVA incubated MPEK. (d) Analysis by Western blot revealed the presence of OVA in lysates of antigen incubated MPEK, presenting the same doublet band as seen with pure OVA protein. $40 \mu \mathrm{g}$ of MPEK lysate per sample were used. Actin served as loading control. (e) To demonstrate antigen transfer to MPEK exosomes, exosomes derived from OVA incubated MPEK were analyzed. Western blot demonstrates the presence of OVA in exosomes and even an enhanced signal intensity when additonal IFN $\gamma$ stimulation of MPEK had occurred. $24 \mu \mathrm{g}$ of lysate per exosome sample were used. Lamin served as loading control. 


\subsection{BMDC take up MPEK-derived exosomes with an increased quantity over time}

Dendritic cells function as professional APC. Depending on their phenotype, immature dendritic cells efficiently take up antigen, whereas mature dendritic cells mainly present it (Banchereau and Steinman 1998). BMDC generated in vitro were considered immature or semi-mature, prior to incubation with exosomes. In line with previous publications for BMDC exposed to DC-derived exosomes (Morelli et al. 2004), BMDC were able to internalize MPEK-derived exosomes as demonstrated by flow cytometry and immunofluorescence using PKH26-labeled exosomes (Fig. 7a and b). The time series of $0.5 \mathrm{~h}, 4 \mathrm{~h}$, and $24 \mathrm{~h}$ of incubation demonstrated an increase of exosome internalization over time, however, showing strong interindividual differences between single BMDC. Since exosomes are too small to be visualized as individual particles by fluorescence microscopy, images depict aggregates of exosomes in a typical granular pattern (Fig. 7c) (Lin et al. 2007), due to exosome accumulation in lysosomes after uptake (Tian et al. 2013). 
a

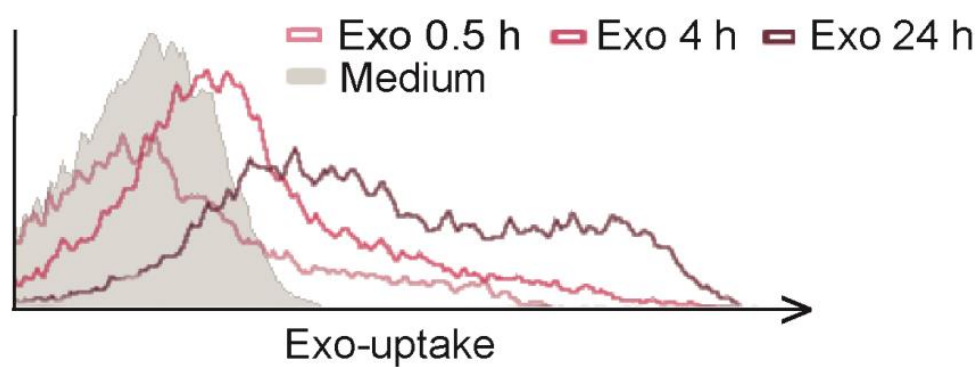

b

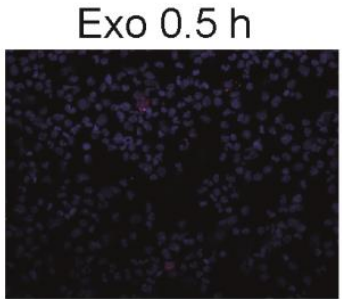

Exo $4 \mathrm{~h}$
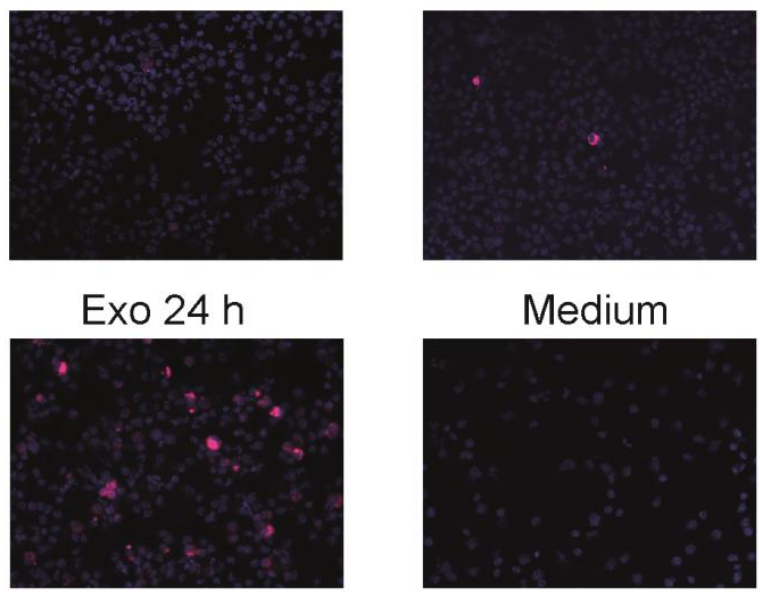

Medium

C
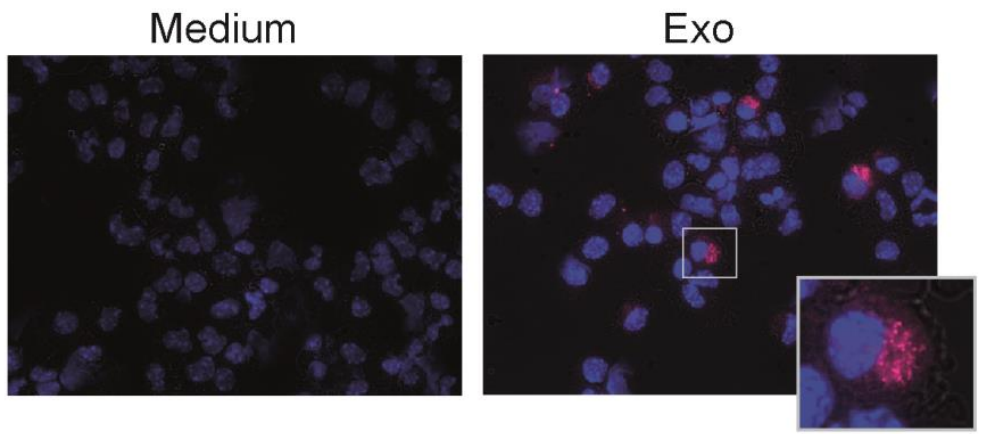

Figure 7: Uptake of MPEK-derived exosomes by BMDC increases over time. To visualize internalization of MPEK-derived exosomes by BMDC, BMDC had been incubated with $10 \mu \mathrm{g} / \mathrm{ml}$ PKH-labeled exosomes. Uptake of MPEK-derived exosomes was analyzed after $0.5 \mathrm{~min}, 4 \mathrm{~h}$, and $24 \mathrm{~h}$ of incubation by (a) flow cytometry and (b) fluorescence microscopy, respectively. For flow cytometry only viable CD11c-positive cells were taken into consideration. (c) Amplification of BMDC in immunofluorescence after $4 \mathrm{~h}$ of incubation with exosomes revealed the typical granular aggregates visible in the cytoplasm. BMDC incubated with normal medium served as negative control. 


\subsection{Exosome-uptake enhances production of IL-6, IL-10, and IL-12 and CD40 expression by BMDC}

As BMDC were considered semi-mature before exosome incubation, the influence of exosome uptake on maturation was examined. Toward this end, BMDC where incubated for $24 \mathrm{~h}$ with different exosomes (Exo +/- IFN $\gamma+/$ - OVA) and phenotype and interleukin profile were analyzed in vitro. Exosome uptake induced BMDC to produce higher amounts of IL-6, IL-10, and IL-12 as measured by ELISA (Fig. 8a). Importantly, incubation of BMDC with medium or OVA as controls did not show any comparable effects. In line with immunostimulatory potential of exosomes (Skokos et al. 2003), uptake led to maturation of BMDC as demonstrated by a significantly enhanced expression of CD40 compared to medium control. However, exosome internalization was not able to influence expression of CD86, MHC I, or MHC II (Fig. 8b). Overall, MPEK-derived exosomes showed a general immunostimulatory effect on BMDC, whereas no significant differences between antigen containing and/or IFN $\gamma$ stimulated exosomes could be observed. 
a

$$
\text { IL-6 [pg/ml] }
$$

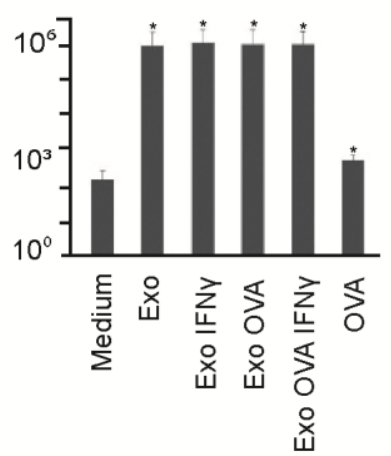

b

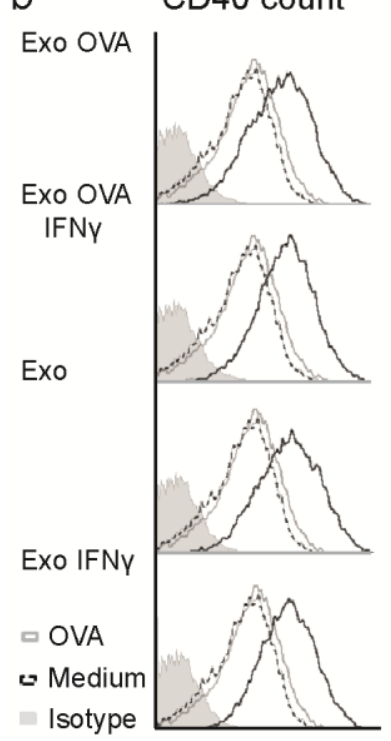

IL-10 [pg/ml]

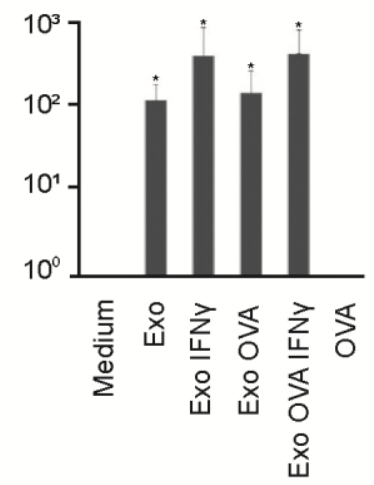

IL-12 [pg/ml]

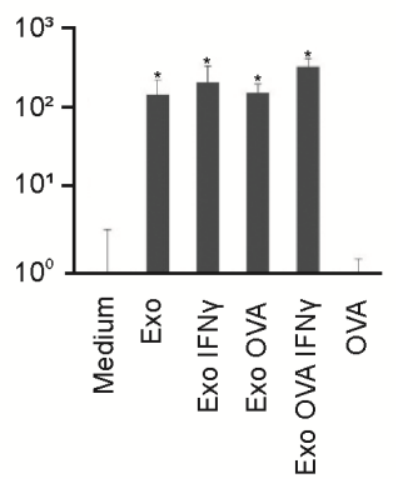

CD86 count

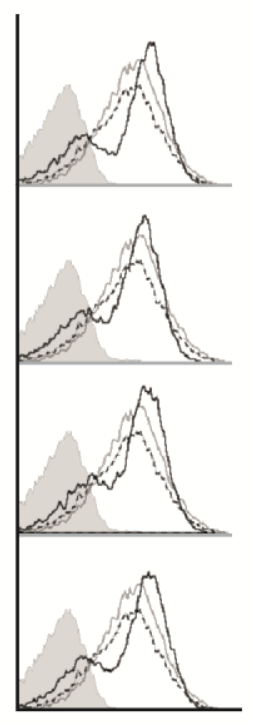

MHC I count

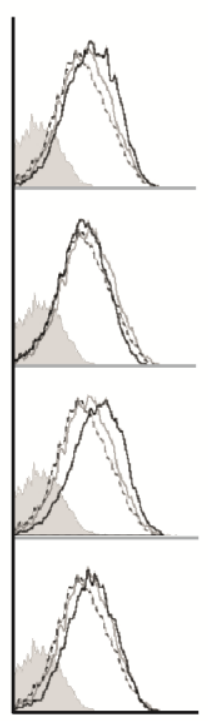

MHC II count

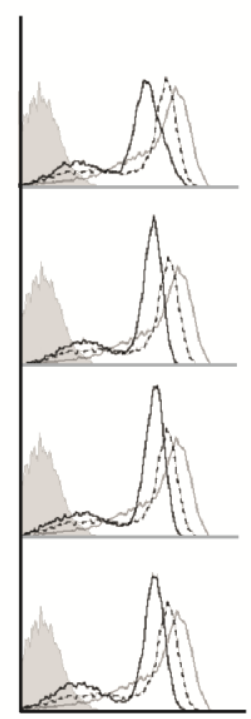

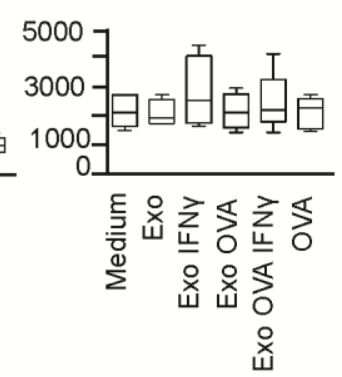

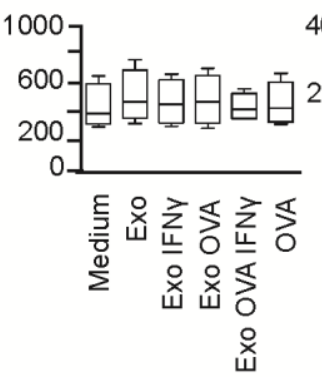

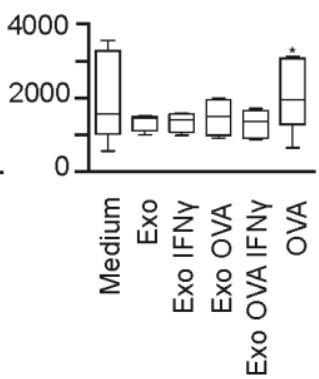

Figure 8: Exosome-loaded BMDC increase IL-6, IL-10, and IL-12 production and CD40 expression. To assess whether MPEK-derived exosomes have an impact on BMDC phenotype and interleukin profile, BMDC were incubated with $10 \mu \mathrm{g} / \mathrm{ml}$ of different loaded exosomes $($ Exo +/- OVA +/- IFN $\gamma$ ). Cytokine production and phenotype were analyzed by (a) ELISA and (b) flow cytometry, respectively. Interleukin production of IL-6, IL-10, and IL-12 was significantly enhanced, whereas with regard to phenotype only the expression of (b) CD40 but not of CD86, MHC I, or MHC II was increased. Only viable and CD11c-positive BMDC were analyzed phenotypically. There were no significant differences regarding the effects detected with different loaded exosomes. * indicates $\mathrm{p}<0.05$ compared to medium incubated BMDC. Statistical analysis was calculated with the rank-sum test with ANOVA-type statistic (Brunner et al. 2001), n = 5. 


\subsection{Antigen-containing exosomes fail to induce direct or BMDC-mediated antigen-specific $T$ cell responses}

To assess whether exosomes deliver OVA protein unbound or its processed peptide derivates bound to MHC molecules, exosomal expression of MHC I and II was investigated by Western blot and proteomic analysis (Fig. 9a, Table 19). Western blot displayed the presence of MHC I in IFN $\gamma$ stimulated as well as control (medium incubated) MPEK, whereas for exosomes, MHC I could only be detected in exosomes derived from IFN $\gamma$ stimulated MPEK. Proteomic analysis of Exo and Exo IFN $\gamma$ confirmed those findings with detection of $\mathrm{H}-2$ class I histocompatibility antigen, L-D alpha chain precursor in samples of Exo IFN $\gamma$. No MHC II molecules could be detected in any preparations, neither of MPEK nor in any of their exosomes. This finding was irrespective of IFN $\gamma$ stimulation.

The question whether MPEK-derived exosomes would elicit antigen-specific $\mathrm{T}$ cell responses, was addressed by in vitro proliferation assays. Given that keratinocytes are non-professional APC, they express very few, if any, costimulatory molecules they could transfer to their exosomes (Nickoloff and Turka 1994). To compensate for this lack of molecules, co-culture experiments with BMDC were conducted. BMDC loaded with antigen-containing exosomes were incubated with CFSE stained CD4- or CD8-positive $\mathrm{T}$ cells derived from OT-I or OT-II mice, respectively. After a total of $72 \mathrm{~h}$ of co-culture, T cells were measured by flow cytometry for CFSE intensity and the supernatant was analyzed for IFN $\gamma$ production (Fig. 9b and c). No significant changes of fluorescence or IFN $\gamma$ production could be detected indicating that antigen-loaded exosomes failed to induce antigen-specific $\mathrm{T}$ cell responses. To test the hypothesis that exosomes could elicit $\mathrm{T}$ cell responses directly, antigen containing and, due to its pivotal role for immune responses, IFN $\gamma$ stimulated exosomes (van Niel et al. 2003) were introduced into the same experimental set up and incubation with either CFSE stained CD4- or CD8-positive $\mathrm{T}$ cells was carried out (Fig. 9d). It was found that OVA-containing IFN $\gamma$ stimulated 
exosomes also failed to induce antigen-specific CD4 or CD8 T cell proliferation. All results were irrespective of additional T cell stimulation with IL-2.

Table 19: MHC expression in MPEK-derived exosomes

\begin{tabular}{lcccc}
\hline Protein name & Exosome & Exosome IFN $\gamma$ & MW (kDa) & Accession no. \\
\hline $\begin{array}{l}\text { H-2 class I histocompatibility } \\
\text { antigen, L-D alpha chain }\end{array}$ & -- & + & 41 & NP_034510 \\
precursor & -- & -- & & \\
MHC II & - & &
\end{tabular}


a $\quad \frac{\text { Exo }}{- \text { IFNy }} \frac{\text { MPEK }}{- \text { IFNy }}$ spleen

$\mathrm{MHC} / 41 \mathrm{kDa}$

actin $43 \mathrm{kDa}$

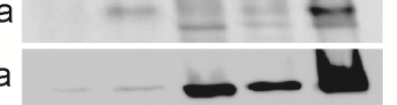

MHC II 32 kDa

$\frac{\text { Exo }}{- \text { IFNy }} \frac{\text { MPEK }}{- \text { IFNy }}$ spleen

actin $43 \mathrm{kDa}$

$\mathrm{b}$
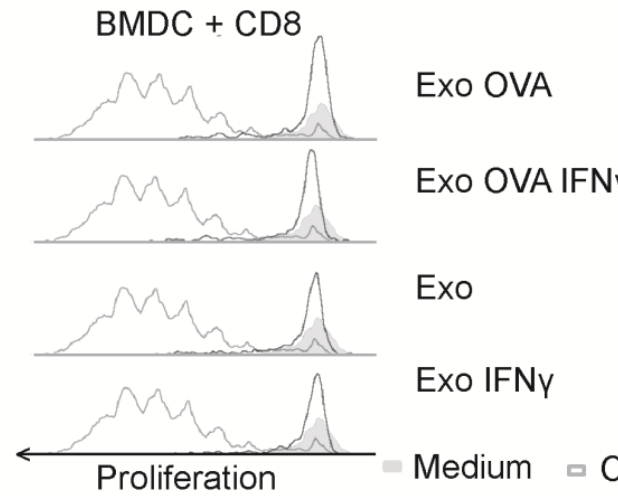

Exo

Exo IFNy

C

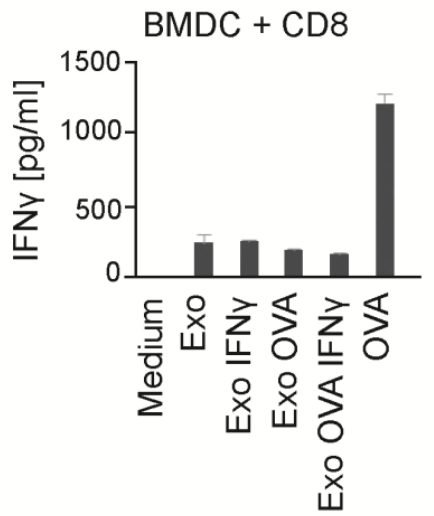

Medium $\square$ OVA $\leftarrow$ Proliferation

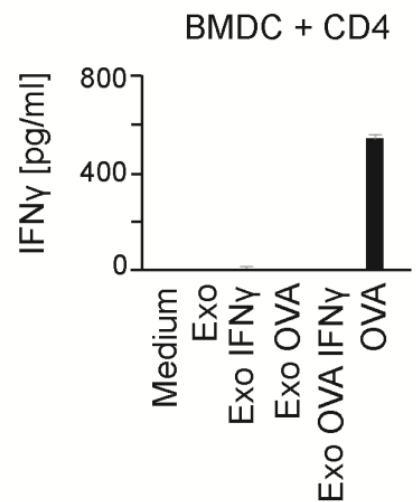

d

CD8

CD4
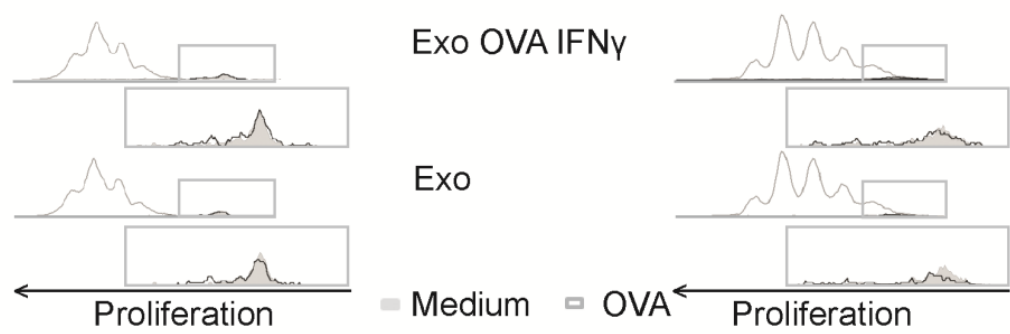

Figure 9: Antigen-loaded exosomes failed to induce antigen-specific $\mathbf{T}$ cell response directly or via BMDC. To analyze whether OVA protein is delivered unbound or bound to MHC molecules in exosomes, MHC I and MHC II expression of MPEK and their exosomes was analyzed by Western blot (a). Spleen lysate served as positive control. (b, c) For functional analysis, exosome-loaded BMDC were incubated for $72 \mathrm{~h}$ with antigen-specific T cells from OT-I or OT-II mice, respectively, and the $\mathrm{T}$ cell response was determined by (b) flow cytometry for proliferation and (c) by ELISA for IFN $\gamma$ production. OVA-loaded BMDC and medium-incubated BMDC served as positive and negative controls, respectively. Analysis of a BMDC:T cell ratio of 1:3 is displayed. (d) Second, antigen-loaded IFN $\gamma$ stimulated exosomes $(10 \mu \mathrm{g} / \mathrm{ml})$ were directly incubated with $\mathrm{T}$ cells, and proliferation was measured by flow cytometry. CD3/CD28 stimulated $\mathrm{T}$ cells and medium incubated $\mathrm{T}$ cells were used as positive and negative controls, respectively. For $\mathrm{T}$ cells to be taken into consideration, cells had to be viable, CD11c-negative, and CD4- or CD8-positive, respectively. Data are depicted as mean $+/$ - standard deviation for triplicate cultures. 


\subsection{Composition of MPEK-derived exosomes is changed under defined conditions modeling clinical settings}

As shown before, exosomes were able to affect BMDC phenotype and interleukin production. To address the question whether environmental conditions were able to affect exosome composition, as demonstrated for IFN $\gamma$ stimulation and MHC expression, MPEK were cultured under different conditions and their exosomes were analyzed by proteomic analysis. Skin diseases are known to affect the cytokine profile of keratinocytes in vivo, as it has been studied in various mouse models (Schön 2008; Spergel et al. 1998). In this experimental set up the cytokine environment of chronic skin diseases was simulated in vitro. In addition to the inflammatory stimulus IFN $\gamma$, the frequent chronic diseases psoriasis and atopic dermatitis display distinctly different patterns of inflammatory mediators. Based on this notion, MPEK were either incubated with IL-17, IL-22, and TNF- $\alpha$ as a typical cytokine profile of psoriasis (Raychaudhuri 2012) or with IL-4 and IL-13 representative for atopic dermatitis (Bieber 2012). Exosomes generated under steady state conditions (medium) were analyzed for comparison. The following table (Table 20) presents an overview of proteins involved in adhesion, cytoskeleton, membrane fusion and transport, metabolism, antigen presentation, protein folding, and signaling. Proteins presented have been defined previously in exosomal preparations as presented in ExoCarta (Mathivanan and Simpson 2009).

The results suggest a specific accumulation of proteins depending on specific conditions. In comparison to exosomes generated under steady state, influence of the changed environmental cytokine profile could be observed in every protein family: 
Table 20: Exosomal composition under different environmental conditions

Exo

\begin{tabular}{|c|c|c|c|c|c|}
\hline medium & $\begin{array}{l}\text { IL-17, } \\
\text { IL-22, } \\
\text { TNF-a }\end{array}$ & $\begin{array}{l}\text { IL-4, } \\
\text { IL-13 }\end{array}$ & IFN $\gamma$ & $\begin{array}{l}\text { MW } \\
(\mathbf{k D a})\end{array}$ & $\begin{array}{l}\text { Accession } \\
\text { no. }\end{array}$ \\
\hline
\end{tabular}

\section{Cell adhesion}

basal cell adhesion

molecule

claudin-1

E-cadherine

integrin $\alpha-6$

lactadherin/ milk fat

globule-EGF factor 8

$\begin{array}{cc}- & + \\ + & + \\ - & - \\ + & + \\ + & + \\ +++++ & +\end{array}$

laminin B1

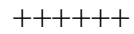

Cytoskeleton

actin $\beta$

actinin $\alpha 1$

cofilin-1

filamin B

+
++
-
+
+

$+68$

EDL23193

$+\quad 23$

NP_057883

$+\quad 98$

P09803

$+\quad 120$

NP_032423

$+$

47

NP_032620

$+\quad+$

$+$

$++++\quad 202$

AAA39407

$+++$

$+$

$+$

$+\quad 42$

NP_001092

$+++\quad+++$

103

NP_598917

$+$

$+\quad 19$

NP_031713

$\begin{array}{ll}+ & \\ -\quad & \end{array}$

NP_598841

keratin 13 type I

Membrane fusion and transport

alix/ programmed cell

death 6-interacting

protein

annexin A1

annexin A4

cation-dependent

mannose-6-phosphate

receptor precursor

rab 10

rab 14

Metabolic enzymes

fatty acid synthase

glucose-6-phosphate

isomerase

glyceraldehyde-3-

phosphate

dehydrogenase

L-lactate

dehydrogenase A

- 48

NP_034792

chain

malate dehydrogenase

1 , cytoplasmic

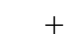

$+$

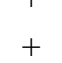

$+$

$++$
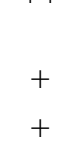

$$
\text { - }
$$

$$
+
$$$$
+
$$

96

NP_035182

$+\quad+\quad 39$

NP_034860

$++\quad+++$

36

NP 038499

$++$

31

NP_034879

$+\quad+\quad 23$

NP_057885

$++$

$++$

NP_080973

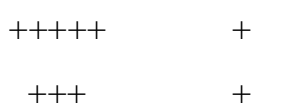

$++++$

$++++$

273

EDL34808

$+++$

$+++$

$+$

63

NP_032181

NP_032110

pyruvate kinase, muscle
$+$

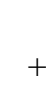

$+$

$+$

$$
+\quad+\quad 36
$$$$
+(+) \quad+(+) \quad 40
$$$$
\text { NP_034829 }
$$

NP_032644

NP_035229 
Exo

\begin{tabular}{|c|c|c|c|c|c|}
\hline medium & $\begin{array}{l}\text { IL-17, } \\
\text { IL-22, } \\
\text { TNF- } \alpha\end{array}$ & $\begin{array}{l}\text { IL-4, } \\
\text { IL-13 }\end{array}$ & IFN $\gamma$ & $\begin{array}{l}\text { MW } \\
(\mathbf{k D a})\end{array}$ & $\begin{array}{l}\text { Accession } \\
\text { no. }\end{array}$ \\
\hline
\end{tabular}

\begin{tabular}{|c|c|c|c|c|c|c|}
\hline MHC molecules & & & & & & \\
\hline $\begin{array}{l}\text { H-2 class I } \\
\text { histocompatibility } \\
\text { antigen, L-D alpha } \\
\text { chain }\end{array}$ & - & - & - & + & 41 & NP_034510 \\
\hline MHC II & - & - & - & - & & \\
\hline \multicolumn{7}{|l|}{ Protein folding } \\
\hline calreticulin precursor & + & + & + & + & 48 & NP_031617 \\
\hline heat shock protein $90 \alpha$ & ++++ & + & ++++ & +++ & 85 & NP_034610 \\
\hline $\begin{array}{l}\text { heat shock protein } 90 \beta \\
\text { protein disulfide }\end{array}$ & + & + & + & $+(+)$ & 92 & NP_032328 \\
\hline $\begin{array}{l}\text { isomerase A3 } \\
\text { precursor }\end{array}$ & + & + & + & + & 57 & NP_031978 \\
\hline \multicolumn{7}{|l|}{ Signaling } \\
\hline $14-3-3 \eta$ & ++ & + & ++ & + & 28 & NP_035868 \\
\hline $14-3-3 \sigma$ & + & + & + & + & 28 & NP_061224 \\
\hline $14-3-3 \varepsilon$ & + & + & + & + & 29 & NP_006752 \\
\hline $\begin{array}{l}\text { guaninenucleotide- } \\
\text { binding } G(\text { i) } \alpha 2\end{array}$ & + & + & + & + & 40 & NP_032164 \\
\hline major vault protein & ++ & + & ++ & ++ & 97 & NP_542369 \\
\hline phospholipase D3 & - & - & + & - & 54 & NP_035246 \\
\hline
\end{tabular}




\section{Discussion}

\subsection{Characterization of MPEK-derived membrane vesicles}

During the last decades, research on exosomes has focused on hematopoietic cells. Thus, little is known about epithelial cell-derived exosomes. In this work, it was demonstrated for the first time that murine keratinocytes produce exosomes under steady state as well as under inflammatory conditions (Figure 5 page 32). Before, exosome production had only been shown for human keratinocytes (Chavez-Muñoz et al. 2008) and other epithelial cells as intestinal epithelial cells (van Niel et al. 2001).

\subsection{Immunological aspects of MPEK-derived exosomes}

\subsubsection{MPEK-derived exosomes contain antigenic information}

Keratinocytes play a pivotal role in the cutaneous immune system. Besides their contribution to the innate immune system (Pivarcsi et al. 2005), they also take part in adaptive immune responses (Nickoloff and Turka 1994). To function as non-professional APC, keratinocytes have to take up antigen for presentation. Analysis by FACS and immunofluorescence microscopy demonstrated a strong increase of fluorescence when MPEK were incubated with FITC-labeled OVA at $37^{\circ} \mathrm{C}$ whereas no change could be detected at $4^{\circ} \mathrm{C}$. This dependence on temperature strongly suggests active antigen uptake instead of unspecific binding. Confocal microscopy and Western blot confirmed these results by demonstrating the presence of OVA via antibody reaction within the cell or cell lysate (Figure 6 page 34). Furthermore, these findings are in line with previous publications demonstrating not only the uptake, but also effective processing and presentation of antigen by keratinocytes (Black et al. 2007). As mentioned previously, exosomes contain a specific protein repertoire consisting of cytosolic and membrane proteins of their mother cell with a specific enrichment of certain proteins (Ratajczak et al. 2006; 
Simpson et al. 2008). As a component of this molecular pattern, antigen internalized by MPEK was also transferred to their exosomes. As expected (Blume et al. 2009), increased allergen uptake by keratinocytes occurs under IFN $\gamma$ stimulation. Lysates of MPEK-derived exosomes showed that their exosomes contained a higher quantity of antigen when MPEK had not only been exposed to the respective antigen but had been stimulated with IFN $\gamma$ as well (Figure 6 page $34)$.

\subsubsection{Immunostimulatory effect of MPEK-derived exosomes on BMDC}

Keratinocytes and DC, which are so-called Langerhans cells within the epidermis, maintain a close regional relationship to each other. In the experimental setting employed here, BMDC took up MPEK-derived exosomes as shown by fluorescence microscopy and FACS analysis (Figure 7 page 36). This finding is partially supported by previous publications, demonstrating BMDC to internalize DC-derived exosomes in vitro (Morelli et al. 2004). The uptake increased over time, with a strong inter-individual difference between particular cells (Figure 7 page 36), a notion that is possibly associated with different states of maturation (Banchereau and Steinman 1998; Morelli et al. 2004).

Keratinocytes are the most abundant cells within the skin. With their key role in the cutaneous immune system, they are able to directly kill or fight invading microbes through the production of antimicrobial peptides (AMP). However, they also link innate and adaptive immunity via AMP- and TLR-dependent activation of DC (Pivarcsi et al. 2005). Because keratinocytes are very numerous and are located adjacent to DC, it is conceivable that they "select" and transfer important information not only via AMP but also via their exosomes to regional DC, similar to the short range mechanism of exosomes of immature DC to spread alloantigen between DC (Montecalvo et al. 2008). This hypothesis is further supported by recent findings suggesting a specific uptake and target selection of exosomes via tetraspanins (Rana and Zoller 2011). 
MPEK-derived exosomes were not only internalized by BMDC but their uptake also influenced BMDC phenotype and interleukin production, indicating an induction of maturation. DC maturation is crucial for the initiation of immune responses and is known to be induced by microbial products and certain cytokines as IL-1 or TNF- $\alpha$ in vivo (Banchereau and Steinman 1998). In vitro, internalized MPEK-derived exosomes induced BMDC to produce high amounts of IL-6, IL-10, and IL-12. Additionally, expression of the surface and maturation marker CD40 was highly increased by uptake of MPEK-derived exosomes, whereas CD86, MHC I, or MHC II expression was not affected (Figure 8 page 38). Other studies demonstrated mast cell-derived exosomes to increase not only CD40 expression of BMDC, but also CD86 and MHC II expression (Skokos et al. 2003). In contrast, blood-borne exosomes did not affect splenic DC phenotype at all (IA ${ }^{\mathrm{b}}$, CD54, CD86) (Morelli et al. 2004). Moreover, MPEK-derived exosomes altered the interleukin profile of BMDC. In recent experiments, a changed interleukin profile of macrophages through melanoma cell-derived exosomes has been demonstrated, which included induction of IL-8 and IL-1Ra but not of IL-6, IL-10, or IL-12. The observed cytokine profile could not be assigned in a strict sense to a $\mathrm{TH} 1$ or $\mathrm{TH} 2$ type response (Marton et al. 2012). Further, trophoblast-derived exosomes were able to upregulate chemokine production of monocytes (amongst others IL-1 $\beta$, IL-6, and TNF $\alpha$ ) (Atay et al. 2010). However, even though MPEK-derived exosomes did influence BMDC phenotype and interleukin profile, this effect was comparable between the different kinds of exosomes (Exo +/- OVA +/- IFN $\gamma$ ). These findings emphasize two major points: the influence of exosomes strongly depends on the cell type of origin and MPEK-derived exosomes seem to have a general but not a specific immunostimulatory effect. With regard to the more complex in vivo situation, DCs are exposed to a multitude of exosomes derived from different cell types. Thus, changes of ratio between the different kinds of exosomes might be more relevant for DC maturation than the kind of exosome itself. 


\subsubsection{Antigen-specific functions of MPEK-derived exosomes}

MPEK-derived exosomes failed to induce an antigen-specific $\mathrm{T}$ cell response alone and via BMDC (Figure 9 page 41). This finding was somewhat surprising. Due to their shortage of co-stimulatory molecules only a couple of exosomes are able to elicit T cell responses directly (Admyre et al. 2006; Kovar et al. 2006). However, several studies have demonstrated that exosomes can stimulate $\mathrm{T}$ cells in the presence of APC (Andre et al. 2002; Andre et al. 2004).

The failure of MPEK-derived exosomes to induce $\mathrm{T}$ cell proliferation via BMDC could be due to the décor of co-stimulatory molecules. Most experiments have been conducted with immune cell-derived exosomes. Immune cells, in comparison to keratinocytes, function as professional instead of non-professional APC and constitutively express a higher abundance of MHC and co-stimulatory molecules (Chavez-Muñoz et al. 2009; Segura et al. 2005b). However, intestinal epithelial cell-derived exosomes elicited a humoral immune response even though these exosomes were free of any co-stimulatory molecules. This study also emphasized the pivotal role of IFN $\gamma$, since only exosomes derived from IFN $\gamma$-stimulated cells were effective (van Niel et al. 2003). In line with our findings that MPEK did not express MHC II under IFN $\gamma$ stimulation, this failure of expression has also been demonstrated for other murine keratinocytes in vitro before (Gaspari and Katz 1988). However, transfer of MHC class II-restricted allopeptides to MHC class II molecules on the surface of APCs seems to be required (Montecalvo et al. 2008), suggesting the independence on MHC II expression of the exosomes' mother cell. In addition, functional failure of too low antigen-loads could have been the reason for the lacking $\mathrm{T}$ cell proliferation. However, in vitro, DCs are able to elicit strong antigen-specific $\mathrm{T}$ cell responses with small antigen amount (nanomolar and picomolar concentrations) (Banchereau and Steinman 1998; Mellman et al. 1998).

Exosomes can be internalized by two independent mechanisms. Either, they are taken up by the endocytic machinery or they directly fuse with the target cell's membrane, releasing its content into the cytoplasm (Thery 2011). The way of internalization strongly influences the shuttle of antigen into different compartments 
and, consequently, the processing and presentation of antigen (Hilmenyuk et al. 2010). If keratinocyte exosomes are channeled into a different pathway than immune cell exosomes, it is conceivable that the differing effects are related to specific shuttle routes.

However, it is also possible that MPEK-derived exosomes did not fail to induce antigen-specific $\mathrm{T}$ cell responses but rather prevented $\mathrm{T}$ cells from proliferation as an anti-inflammatory mechanism. Along this line of speculation, keratinocytederived exosomes could exert protective functions, thus down-regulating excessive immune reactions. Indeed, serum-derived exosomes did prevent allergic sensitization in mice with allergic asthma (Almqvist et al. 2008). Interestingly, the immune-stimulating capacity of DC-derived exosomes significantly depends on the state of maturation. As mature DC-derived exosomes are considered the most potent immunostimulatory exosomes (Segura et al. 2005a; Zitvogel et al. 1998), immature DC-derived exosomes have immunosuppressive effects instead. The differential expression of co-stimulatory molecules is a possible explanation for this notion (Ruffner et al. 2009; Yin et al. 2013). However, with regards to their expression of co-stimulatory molecules, keratinocyte-derived exosomes are much more similar to immature DC-derived exosomes than to mature DC-derived ones (Chavez-Muñoz et al. 2009; Yin et al. 2013), suggesting an anti-inflammatory rather than a proinflammatory immunological role. In vivo, this finding could imply an anti-inflammatory effect of keratinocyte-derived exosomes for physiological and pathological immune processes.

\subsection{Bidirectional entanglement of environmental conditions and exosomal composition}

Analysis of exosomes generated under the influence of "atopic" or "psoriatic" cytokine cocktails highlighted the profound environmental regulation of exosomal composition that affected virtually all functional fields (Table 20 page 43). Compared to primary keratinocytes, the use of a cell line provided more stability and reproducibility of the prepared exosomes, thus achieving better conditions to 
compare the proteomic composition. Given that exosomes contain a distinctive assembly of proteins depending on the cell type they originate from (Simpson et al. 2008), this specific fingerprint hints at the mother cell and/or its state of maturation, as demonstrated for dendritic cells and human keratinocytes (Chavez-Muñoz et al. 2009; Yin et al. 2013). Therefore, it is possible to generate different exosomes by interleukin treatment of the mother cell. Exosomes of "conventional" monocyte-derived DC (MDDC) and IL-4/IL-3-generated MDDC phenotypically reflected their MDDC of origin (Johansson et al. 2008). However, a selective enrichment of proteins prevents exosomes from being a miniature format of the cell itself (Ratajczak et al. 2006). In line, investigations of exosomes derived of primary cancer cells and metastatic cells discovered selective enrichment of certain proteins involved in metastasis and signaling in metastatic cell-derived exosomes ( $\mathrm{Ji}$ et al. 2013). The specific protein composition of exosomes renders them as possible biomarkers. Especially in the fields of oncology and nephropathies, a lot of effort has been put on such biomarkers to improve early diagnosis and to predict the course of the disease (Dear et al. 2013; Simpson et al. 2009). Besides this diagnostic potential, exosomes may also provide therapeutic alternatives, as a variety of immunosuppressive exosomes for treating arthritis has been proposed (Yang and Robbins 2012). Moreover, IL-10 treatment of DC generated immunosuppressive exosomes, which were able to suppress inflammation and collagen-induced arthritis (Kim et al. 2005). Owing to their stability to phenotypic changes after injection, exosomes may qualify for therapeutic use (Zitvogel et al. 1998). Contrariwise, exosomes may also provide a therapeutic target. Circumstantial evidence suggests that extracellular vesicles derived from Staphylococcus aureus are involved in the pathogenesis of atopic dermatitis (Hong et al. 2010). These findings are in line with a proinflammatory role of epithelial cell-derivd exosomes and further emphasize a pathophysiological role of exosomes in various diseases (Kulshreshtha et al. 2013). Thus, diminution of these vesicles is predicted to ameliorate certain disorders. The mutual influence of exosomes and the environment emphasizes the possible entanglement of exosomes in (patho)physiological processes and establishes a role for exosomes as potential therapeutic tools as well as targets. 


\subsection{Further considerations}

Notwithstanding the demonstration of new functions of murine keratinocyte-derived exosomes, this study has raised further questions and has some obvious limitations:

a) The BMDC and $\mathrm{T}$ cells used were generated for every experiment from different mice. Although the experimental animals were raised under identical conditions and were used at the same age, such biological systems may show considerable inter-individual variations.

b) The experiments provided evidence for an immunomodulatory function of exosomes. Yet, it remains to be resolved whether keratinocyte-derived exosomes have a stimulatory or rather an immunosuppressive role in the cutaneous immune system and through which factors and pathways these effects are mediated. A feasible approach could be the demonstration of OVA in BMDC to exclude insufficient OVA transfer. Otherwise, it is not clear which quantity is needed to elicit an antigen-specific $\mathrm{T}$ cell response. Even if OVA would not have been visualized in BMDC, BMDC could still elicit a T cell response. Further, exosomes specifically influenced CD40 expression but not CD86, MHC I, or MHC II, thus strengthening the point of a specific response.

c) Due to the lack of comparable mouse models and syngeneic DC in human models, the experimental setup cannot be transferred easily to human keratinocytes. However, the results would be supported by the demonstration of similar effects when using different murine cell lines and primary keratinocytes. 


\section{Summary and Conclusion}

Keratinocytes are able to influence cutaneous immunity by taking part in innate as well as in adaptive immune processes. To fulfill this task, the production of soluble factors has a key role. Exosomes, small membrane vesicles of endocytic origin and secreted by a variety of cells, may modify immune responses. However, little is known about the immunological function of keratinocyte-derived exosomes.

To address this question, the murine keratinocyte cell line MPEK was cultured in vitro, and the production of exosomes has been demonstrated. These exosomes were internalized by bone marrow-derived dendritic cells (BMDC), where they induced production of high amounts of IL-6, IL-10, and IL-12 as well as increased surface expression of CD40. When MPEK were incubated with antigen, they transferred it to their exosomes. However, antigen-loaded exosomes failed to induce an antigen-specific $\mathrm{T}$ cell response directly or via BMDC. When environmental conditions, mimicked by cytokine cocktails characteristic for two of the most common chronic inflammatory skin disorders, atopic dermatitis or psoriasis, were modulated, a profound impact on the molecular repertoire of exosomes was found. The specifically altered components comprised virtually all functional fields.

Even though MPEK-derived exosomes did not elicit an antigen-specific $\mathrm{T}$ cell response, they were clearly able to influence BMDC function and phenotype. Further, interleukins and IFN $\gamma$ markedly influenced the molecular exosome composition. Together, these findings suggest an immunomodulatory function for MPEK-derived exosomes and a crucial effect of environmental conditions on exosome composition end presumably even function. 


\section{Literature}

Admyre C, Grunewald J, Thyberg J, Gripenback S, Tornling G, Eklund A, Scheynius A, Gabrielsson S (2003): Exosomes with major histocompatibility complex class II and co-stimulatory molecules are present in human BAL fluid. Eur Respir J 22, 578-583

Admyre C, Johansson SM, Paulie S, Gabrielsson S (2006): Direct exosome stimulation of peripheral human $\mathrm{T}$ cells detected by ELISPOT. Eur $J$ Immunol 36, 1772-1781

Admyre C, Bohle B, Johansson SM, Focke-Tejkl M, Valenta R, Scheynius A, Gabrielsson S (2007): B cell-derived exosomes can present allergen peptides and activate allergen-specific $\mathrm{T}$ cells to proliferate and produce $\mathrm{TH} 2$-like cytokines. J Allergy Clin Immunol $\underline{120}$, 1418-1424

Almqvist N, Lonnqvist A, Hultkrantz S, Rask C, Telemo E (2008): Serum-derived exosomes from antigen-fed mice prevent allergic sensitization in a model of allergic asthma. Immunology $\underline{125}, 21-27$

Andre F, Schartz NE, Movassagh M, Flament C, Pautier P, Morice P, Pomel C, Lhomme C, Escudier B, Le Chevalier T, et al. (2002): Malignant effusions and immunogenic tumour-derived exosomes. Lancet 360, 295-305

Andre F, Chaput N, Schartz NE, Flament C, Aubert N, Bernard J, Lemonnier F, Raposo G, Escudier B, Hsu DH, et al. (2004): Exosomes as potent cell-free peptide-based vaccine. I. Dendritic cell-derived exosomes transfer functional MHC class I/peptide complexes to dendritic cells. J Immunol 172, 21262136

Atay S, Gercel-Taylor C, Suttles J, Mor G, Taylor DD (2010): Trophoblast-derived exosomes mediate monocyte recruitment and differentiation. Am J Reprod Immunol 65, 65-77

Babst M (2005): A protein's final ESCRT. Traffic $\underline{6}, 2-9$

Banchereau J, Steinman RM (1998): Dendritic cells and the control of immunity. Nature $\underline{392}, 245-252$

Bieber T (2012): Atopic dermatitis 2.0: from the clinical phenotype to the molecular taxonomy and stratified medicine. Allergy $\underline{67}, 1475-1482$

Black AP, Ardern-Jones MR, Kasprowicz V, Bowness P, Jones L, Bailey AS, Ogg GS (2007): Human keratinocyte induction of rapid effector function in antigen-specific memory CD4+ and CD8+ T cells. Eur J Immunol 37, 14851493 
Blume C, Foerster S, Gilles S, Becker WM, Ring J, Behrendt H, Petersen A, TraidlHoffmann C (2009): Human epithelial cells of the respiratory tract and the skin differentially internalize grass pollen allergens. J Invest Dermatol 129 , 1935-1944

Braun A, Bewersdorff M, Lintelmann J, Matuschek G, Jakob T, Göttlicher M, Schober W, Buters JT, Behrendt H, Mempel M (2010): Differential impact of diesel particle composition on pro-allergic dendritic cell function. Toxicol Sci $\underline{113}, 85-94$

Brunner E, Domhof S, Langer F: Nonparametric Analysis of Longitudinal Data in Factorial Experiments. Wiley \& Sons, New York 2001

Caby MP, Lankar D, Vincendeau-Scherrer C, Raposo G, Bonnerot C (2005): Exosomal-like vesicles are present in human blood plasma. Int Immunol 17, 879-887

Chaput N, Thery C (2011): Exosomes: immune properties and potential clinical implementations. Semin Immunopathol $\underline{33}$, 419-440

Chavez-Muñoz C, Morse J, Kilani R, Ghahary A (2008): Primary human keratinocytes externalize stratifin protein via exosomes. J Cell Biochem $\underline{104}$, 2165-2173

Chavez-Muñoz C, Kilani RT, Ghahary A (2009): Profile of exosomes related proteins released by differentiated and undifferentiated human keratinocytes. J Cell Physiol 221, 221-231

Cogswell JP, Ward J, Taylor IA, Waters M, Shi Y, Cannon B, Kelnar K, Kemppainen J, Brown D, Chen C, et al. (2008): Identification of miRNA changes in Alzheimer's disease brain and CSF yields putative biomarkers and insights into disease pathways. J Alzheimers Dis 14, 27-41

Dear JW, Street JM, Bailey MA (2013): Urinary exosomes: A reservoir for biomarker discovery and potential mediators of intrarenal signalling. Proteomics $\underline{13}$, 1572-1580

Fevrier B, Vilette D, Archer F, Loew D, Faigle W, Vidal M, Laude H, Raposo G (2004): Cells release prions in association with exosomes. Proc Natl Acad Sci U S A 101, 9683-9688

Gaspari AA, Katz SI (1988): Induction and functional characterization of class II MHC (Ia) antigens on murine keratinocytes. J Immunol 140, 2956-2963

Harding C, Heuser J, Stahl P (1983): Receptor-mediated endocytosis of transferrin and recycling of the transferrin receptor in rat reticulocytes. J Cell Biol 97, 329-339 
Hilmenyuk T, Bellinghausen I, Heydenreich B, Ilchmann A, Toda M, Grabbe S, Saloga J (2010): Effects of glycation of the model food allergen ovalbumin on antigen uptake and presentation by human dendritic cells. Immunology $\underline{129}, 437-445$

Hong SW, Kim MR, Lee EY, Kim JH, Kim YS, Jeon SG, Yang JM, Lee BJ, Pyun BY, Gho YS, et al. (2010): Extracellular vesicles derived from Staphylococcus aureus induce atopic dermatitis-like skin inflammation. Allergy 66, 351-359

Iwasaki A, Medzhitov R (2004): Toll-like receptor control of the adaptive immune responses. Nat Immunol $\underline{5}$, 987-995

Ji H, Greening DW, Barnes TW, Lim JW, Tauro BJ, Rai A, Xu R, Adda C, Mathivanan S, Zhao W, et al. (2013): Proteome profiling of exosomes derived from human primary and metastatic colorectal cells reveal differential expression of key metastatic factors and signal transduction components. Proteomics $\underline{13}$, 1672-1686

Johansson SM, Admyre C, Scheynius A, Gabrielsson S (2008): Different types of in vitro generated human monocyte-derived dendritic cells release exosomes with distinct phenotypes. Immunology $\underline{123}, 491-499$

Johnstone RM, Bianchini A, Teng K (1989): Reticulocyte maturation and exosome release: transferrin receptor containing exosomes shows multiple plasma membrane functions. Blood $\underline{74}, 1844-1851$

Kim BS, Miyagawa F, Cho YH, Bennett CL, Clausen BE, Katz SI (2009): Keratinocytes function as accessory cells for presentation of endogenous antigen expressed in the epidermis. J Invest Dermatol 129, 2805-2817

Kim SH, Lechman ER, Bianco N, Menon R, Keravala A, Nash J, Mi Z, Watkins SC, Gambotto A, Robbins PD (2005): Exosomes derived from IL-10-treated dendritic cells can suppress inflammation and collagen-induced arthritis. $J$ Immunol 174, 6440-6448

Kovar M, Boyman O, Shen X, Hwang I, Kohler R, Sprent J (2006): Direct stimulation of $\mathrm{T}$ cells by membrane vesicles from antigen-presenting cells. Proc Natl Acad Sci U S A $\underline{103}$, 11671-11676

Kulshreshtha A, Ahmad T, Agrawal A, Ghosh B (2013): Proinflammatory role of epithelial cell-derived exosomes in allergic airway inflammation. J Allergy Clin Immunol 131, 1194-1203, 1203 e1191-1114

Lakkaraju A, Rodriguez-Boulan E (2008): Itinerant exosomes: emerging roles in cell and tissue polarity. Trends Cell Biol 18, 199-209 
Lin WJ, Duffy A, Chen CY (2007): Localization of AU-rich element-containing mRNA in cytoplasmic granules containing exosome subunits. J Biol Chem 282, 19958-19968

Lutz MB, Kukutsch N, Ogilvie AL, Rössner S, Koch F, Romani N, Schuler G (1999): An advanced culture method for generating large quantities of highly pure dendritic cells from mouse bone marrow. J Immunol Methods $\underline{223}, 77-92$

Marton A, Vizler C, Kusz E, Temesfoi V, Szathmary Z, Nagy K, Szegletes Z, Varo G, Siklos L, Katona RL, et al. (2012): Melanoma cell-derived exosomes alter macrophage and dendritic cell functions in vitro. Immunol Lett $\underline{148}, 34-$ 38

Mathivanan S, Simpson RJ (2009): ExoCarta: A compendium of exosomal proteins and RNA. Proteomics $\underline{9}$, 4997-5000

Mathivanan S, Fahner CJ, Reid GE, Simpson RJ (2012): ExoCarta 2012: database of exosomal proteins, RNA and lipids. Nucleic Acids Res 40, D1241-1244

Mellman I, Steinman RM (2001): Dendritic cells: specialized and regulated antigen processing machines. Cell $\underline{106}, 255-258$

Mellman I, Turley SJ, Steinman RM (1998): Antigen processing for amateurs and professionals. Trends Cell Biol $\underline{8}, 231-237$

Mempel M, Kalali BN, Ollert M, Ring J (2007): Toll-like receptors in dermatology. Dermatol Clin 25, 531-540

Michael A, Bajracharya SD, Yuen PS, Zhou H, Star RA, Illei GG, Alevizos I (2010): Exosomes from human saliva as a source of microRNA biomarkers. Oral Dis 16, 34-38

Montecalvo A, Shufesky WJ, Stolz DB, Sullivan MG, Wang Z, Divito SJ, Papworth GD, Watkins SC, Robbins PD, Larregina AT, et al. (2008): Exosomes as a short-range mechanism to spread alloantigen between dendritic cells during T cell allorecognition. J Immunol 180, 3081-3090

Morelli AE, Larregina AT, Shufesky WJ, Sullivan ML, Stolz DB, Papworth GD, Zahorchak AF, Logar AJ, Wang Z, Watkins SC, et al.(2004): Endocytosis, intracellular sorting, and processing of exosomes by dendritic cells. Blood $\underline{104}, 3257-3266$

Nguyen DG, Booth A, Gould SJ, Hildreth JE (2003): Evidence that HIV budding in primary macrophages occurs through the exosome release pathway. $J$ Biol Chem 278, 52347-52354 
Nickoloff BJ, Turka LA (1994): Immunological functions of non-professional antigen-presenting cells: new insights from studies of T-cell interactions with keratinocytes. Immunol Today 15, 464-469

Pan BT, Johnstone RM (1983): Fate of the transferrin receptor during maturation of sheep reticulocytes in vitro: selective externalization of the receptor. Cell $\underline{33}$, 967-978

Pant S, Hilton H, Burczynski ME (2012): The multifaceted exosome: biogenesis, role in normal and aberrant cellular function, and frontiers for pharmacological and biomarker opportunities. Biochem Pharmacol $\underline{83}$, 1484-1494

Pivarcsi A, Nagy I, Lajos K (2005): Innate Immunity in the Skin: How Keratinocytes Fight Against Pathogens. Current Immunology 1, 29-42

Prado N, Marazuela EG, Segura E, Fernandez-Garcia H, Villalba M, Thery C, Rodriguez R, Batanero E (2008): Exosomes from bronchoalveolar fluid of tolerized mice prevent allergic reaction. J Immunol 181, 1519-1525

Rana S, Zoller M (2011): Exosome target cell selection and the importance of exosomal tetraspanins: a hypothesis. Biochem Soc Trans 39, 559-562

Raposo G, Nijman HW, Stoorvogel W, Liejendekker R, Harding CV, Melief CJ, Geuze HJ (1996): B lymphocytes secrete antigen-presenting vesicles. J Exp Med $\underline{183}, 1161-1172$

Ratajczak J, Miekus K, Kucia M, Zhang J, Reca R, Dvorak P, Ratajczak MZ (2006): Embryonic stem cell-derived microvesicles reprogram hematopoietic progenitors: evidence for horizontal transfer of mRNA and protein delivery. Leukemia $\underline{20}, 847-856$

Raychaudhuri SP (2012): A Cutting Edge Overview: Psoriatic Disease. Clin Rev Allergy Immunol 44, 109-113

Ruffner MA, Kim SH, Bianco NR, Francisco LM, Sharpe AH, Robbins PD (2009): B7-1/2, but not PD-L1/2 molecules, are required on IL-10-treated tolerogenic DC and DC-derived exosomes for in vivo function. Eur $J$ Immunol 39, 3084-3090

Sanderson MP, Keller S, Alonso A, Riedle S, Dempsey PJ, Altevogt P (2008): Generation of novel, secreted epidermal growth factor receptor (EGFR/ErbB1) isoforms via metalloprotease-dependent ectodomain shedding and exosome secretion. J Cell Biochem 103, 1783-1797

Schön MP (2008): Animal models of psoriasis: a critical appraisal. Exp Dermatol $\underline{17}, 703-712$ 
Segura E, Amigorena S, Thery C (2005a): Mature dendritic cells secrete exosomes with strong ability to induce antigen-specific effector immune responses. Blood Cells Mol Dis 35, 89-93

Segura E, Nicco C, Lombard B, Veron P, Raposo G, Batteux F, Amigorena S, Thery C (2005b): ICAM-1 on exosomes from mature dendritic cells is critical for efficient naive T-cell priming. Blood 106, 216-223

Shevchenko A, Wilm M, Vorm O, Mann M (1996): Mass spectrometric sequencing of proteins silver-stained polyacrylamide gels. Anal Chem $\underline{68}, 850-858$

Simpson RJ, Jensen SS, Lim JW (2008): Proteomic profiling of exosomes: current perspectives. Proteomics $\underline{8}, 4083-4099$

Simpson RJ, Lim JW, Moritz RL, Mathivanan S (2009): Exosomes: proteomic insights and diagnostic potential. Expert Rev Proteomics $\underline{6}, 267-283$

Skokos D, Le Panse S, Villa I, Rousselle JC, Peronet R, David B, Namane A, Mecheri S (2001): Mast cell-dependent B and T lymphocyte activation is mediated by the secretion of immunologically active exosomes. $J$ Immunol $\underline{166}, 868-876$

Skokos D, Botros HG, Demeure C, Morin J, Peronet R, Birkenmeier G, Boudaly S, Mecheri S (2003): Mast cell-derived exosomes induce phenotypic and functional maturation of dendritic cells and elicit specific immune responses in vivo. J Immunol $\underline{170}, 3037-3045$

Spergel JM, Mizoguchi E, Brewer JP, Martin TR, Bhan AK, Geha RS (1998): Epicutaneous sensitization with protein antigen induces localized allergic dermatitis and hyperresponsiveness to methacholine after single exposure to aerosolized antigen in mice. J Clin Invest 101, 1614-1622

Thery C (2011): Exosomes: secreted vesicles and intercellular communications. F1000 Biol Rep $\underline{3}: 15$

Thery C, Zitvogel L, Amigorena S (2002): Exosomes: composition, biogenesis and function. Nat Rev Immunol 2, 569-579

Thery C, Amigorena S, Raposo G, Clayton A: Isolation and characterization of exosomes from cell culture supernatants and biological fluids; in: Current protocols in Cell Biology; Editors JS Bonifacino, M Dasso, JB Harford, J Lippincott-Schwartz, KM Yamada a.o., Wiley \& Sons, New York 2006, 3.22.1-3.22.29

Thery C, Ostrowski M, Segura E (2009): Membrane vesicles as conveyors of immune responses. Nat Rev Immunol 9, 581-593

Tian T, Zhu YL, Hu FH, Wang YY, Huang NP, Xiao ZD (2013): Dynamics of exosome internalization and trafficking. J Cell Physiol 228, 1487-1495 
Valadi H, Ekstrom K, Bossios A, Sjostrand M, Lee JJ, Lotvall JO (2007): Exosome-mediated transfer of mRNAs and microRNAs is a novel mechanism of genetic exchange between cells. Nat Cell Biol $\underline{9}, 654-659$

van Niel G, Raposo G, Candalh C, Boussac M, Hershberg R, Cerf-Bensussan N, Heyman M (2001): Intestinal epithelial cells secrete exosome-like vesicles. Gastroenterology 121, 337-349

van Niel G, Mallegol J, Bevilacqua C, Candalh C, Brugiere S, Tomaskovic-Crook E, Heath JK, Cerf-Bensussan N, Heyman M (2003): Intestinal epithelial exosomes carry MHC class II/peptides able to inform the immune system in mice. Gut 52, 1690-1697

Viaud S, Thery C, Ploix S, Tursz T, Lapierre V, Lantz O, Zitvogel L, Chaput N (2010): Dendritic cell-derived exosomes for cancer immunotherapy: what's next? Cancer Res $\underline{70}$, 1281-1285

Wright CS (1984): Structural comparison of the two distinct sugar binding sites in wheat germ agglutinin isolectin II. J Mol Biol 178, 91-104

Xiao D, Ohlendorf J, Chen Y, Taylor DD, Rai SN, Waigel S, Zacharias W, Hao H, McMasters KM (2012): Identifying mRNA, MicroRNA and Protein Profiles of Melanoma Exosomes. PLoS One $\underline{7}$, e46874

Yang C, Robbins PD (2012): Immunosuppressive exosomes: a new approach for treating arthritis. Int J Rheumatol 2012, 573528

Yin W, Ouyang S, Li Y, Xiao B, Yang H (2013): Immature dendritic cell-derived exosomes: a promise subcellular vaccine for autoimmunity. Inflammation $\underline{36}, 232-240$

Zal T, Volkmann A, Stockinger B (1994): Mechanisms of tolerance induction in major histocompatibility complex class II-restricted $\mathrm{T}$ cells specific for a blood-borne self-antigen. J Exp Med 180, 2089-2099

Zhou H, Yuen PS, Pisitkun T, Gonzales PA, Yasuda H, Dear JW, Gross P, Knepper MA, Star RA (2006): Collection, storage, preservation, and normalization of human urinary exosomes for biomarker discovery. Kidney Int $\underline{69}, 1471-1476$

Zitvogel L, Regnault A, Lozier A, Wolfers J, Flament C, Tenza D, RicciardiCastagnoli P, Raposo G, Amigorena S (1998): Eradication of established murine tumors using a novel cell-free vaccine: dendritic cell-derived exosomes. Nat Med $\underline{4}, 594-600$ 


\section{Appendix}

\subsection{Supplemental data}

Table 21: CD40 MFI

\begin{tabular}{lcccccc} 
BMDC & medium & Exo & Exo IFN $\gamma$ & Exo OVA & $\begin{array}{c}\text { Exo OVA } \\
\text { IFN } \gamma\end{array}$ & OVA \\
\hline Exp: 1 & 634 & - & 1745 & - & 1627 & 775 \\
Exp: 2 & 554 & 1071 & - & 1352 & 1393 & 610 \\
Exp: 3 & 920 & 2962 & 2744 & 2558 & 2789 & 1103 \\
Exp: 4 & 850 & 1840 & 1912 & 1296 & 1231 & 852 \\
Exp: 5 & 478 & 1177 & 884 & 993 & 948 & 574
\end{tabular}

Table 22: CD86 MFI

\begin{tabular}{lcccccc} 
BMDC & medium & Exo & Exo IFN $\gamma$ & Exo OVA & $\begin{array}{c}\text { Exo OVA } \\
\text { IFN } \gamma\end{array}$ & OVA \\
\hline Exp: 1 & 2136 & - & 4405 & - & 4116 & 2290 \\
Exp: 2 & 1807 & 1803 & - & 2175 & 2207 & 1657 \\
Exp: 3 & 1529 & 1755 & 1673 & 1462 & 1459 & 1486 \\
Exp: 4 & 2705 & 2736 & 2981 & 2955 & 2373 & 2742 \\
Exp: 5 & 2739 & 2078 & 2097 & 2101 & 2216 & 2457
\end{tabular}

Table 23: MHC I MFI

\begin{tabular}{lcccccc} 
BMDC & medium & Exo & Exo IFN $\gamma$ & Exo OVA & $\begin{array}{c}\text { Exo OVA } \\
\text { IFN } \gamma\end{array}$ & OVA \\
\hline Exp: 1 & 347 & - & 401 & - & 364 & 352 \\
Exp: 2 & 396 & 471 & - & 515 & 503 & 434 \\
Exp: 3 & 655 & 769 & 667 & 708 & 567 & 674 \\
Exp: 4 & 551 & 483 & 519 & 436 & 426 & 552 \\
Exp: 5 & 305 & 329 & 309 & 295 & 361 & 322
\end{tabular}


Table 24: MHC II MFI

\begin{tabular}{lcccccc} 
BMDC & medium & Exo & Exo IFN $\gamma$ & Exo OVA & $\begin{array}{c}\text { Exo OVA } \\
\text { IFN } \gamma\end{array}$ & OVA \\
\hline Exp: 1 & 1506 & - & 3319 & - & 3104 & 1684 \\
Exp: 2 & 7524 & 3265 & - & 4380 & 3568 & 6637 \\
Exp: 3 & 3525 & 3266 & 3064 & 2864 & 2242 & 4211 \\
Exp: 4 & 3365 & 2392 & 2350 & 2203 & 2124 & 4282 \\
Exp: 5 & 6384 & 3427 & 3585 & 3915 & 3823 & 6446
\end{tabular}

Table 25: IL-6 pg/ml

\begin{tabular}{lcccccc} 
BMDC & medium & Exo & Exo IFN $\gamma$ & Exo OVA & $\begin{array}{c}\text { Exo OVA } \\
\text { IFN } \gamma\end{array}$ & OVA \\
\hline Exp: 1 & 94 & - & 196049 & - & 259927 & 388 \\
Exp: 2 & 55 & 67627 & - & 150508 & 190331 & 261 \\
Exp: 3 & 135 & 250644 & 305798 & 137684 & 262485 & 447 \\
Exp: 4 & 297 & 1398414 & 1586590 & 1605211 & 1626537 & 695 \\
Exp: 5 & 93 & 227987 & 204520 & 223765 & 270825 & 335
\end{tabular}

Table 26: IL-10 pg/ml

\begin{tabular}{lcccccc} 
BMDC & medium & Exo & Exo IFN $\gamma$ & Exo OVA & $\begin{array}{c}\text { Exo OVA } \\
\text { IFN } \gamma\end{array}$ & OVA \\
\hline Exp: 1 & 0 & - & 1046 & - & 1013 & 0 \\
Exp: 2 & 0 & 403 & - & 786 & 709 & 0 \\
Exp: 3 & 0 & 154 & 249 & 64 & 153 & 0 \\
Exp: 4 & 0 & 147 & 200 & 309 & 271 & 0 \\
Exp: 5 & 0 & 158 & 114 & 149 & 141 & 0
\end{tabular}


Table 27: IL-12 pg/ml

\begin{tabular}{lcccccc} 
BMDC & medium & Exo & Exo IFN $\gamma$ & Exo OVA & $\begin{array}{c}\text { Exo OVA } \\
\text { IFN } \gamma\end{array}$ & OVA \\
\hline Exp: 1 & 0 & - & 142 & - & 281 & 0 \\
Exp: 2 & 0 & 42 & - & 121 & 308 & 0 \\
Exp: 3 & 0 & 175 & 302 & 87 & 211 & 2 \\
Exp: 4 & 0 & 124 & 148 & 161 & 161 & 0 \\
Exp: 5 & 5 & 113 & 83 & 104 & 220 & 0
\end{tabular}

Table 28: Exosome production $\mu \mathrm{g} / \mu \mathrm{l}$

\begin{tabular}{lllllllllll} 
Exp & 1 & 2 & 3 & 4 & 5 & 6 & 7 & 8 & 9 & 10 \\
\hline Exo & 1,05 & 1,70 & 3,00 & 1,00 & 0,28 & 0,30 & 0,54 & 0,54 & 0,98 & 0,80 \\
Exo IFNץ & 0,70 & 1,90 & 2,50 & 1,30 & 0,27 & 0,34 & 0,28 & 0,60 & 0,71 & 0,63
\end{tabular}

\subsection{Publications}

\subsubsection{Publications}

Kotzerke K, Mempel M, Aung T, Wulf GG, Urlaub H, Wenzel D, Schön MP, Braun A (2013): Immunostimulatory activity of murine keratinocyte-derived exosomes. Exp Dermatol 10, 650-655

\subsubsection{Presentations with published abstract}

Oral presentation and poster presentation at the $42^{\text {nd }}$ Annual ESDR Meeting in Venice and thus an abstract has been published:

Kotzerke K, Aung T, Wulf GG, Urlaub H, Wenzel D, Schön MP, Mempel M, Braun A (2012): Immunostimulatory effects of exosomes from murine kerationcytes. J Invest Dermatol 132, S1 


\section{Curriculum Vitae}

Mein Name ist Kristina Kotzerke, ich wurde am 31.05.1988 in Hannover als Tochter von Kristin Kotzerke, geb. Trautschold, und Jörg Kotzerke, geboren.

In den Jahren 1994-98 besuchte ich die Grundschule Großburgwedel, um 1998 für zwei Jahre auf die Orientierungsstufe Burgwedel zu wechseln. Ab 2000 besuchte ich das Gymnasium Großburgwedel, an dem ich 2007 meine Hochschulreife erwarb (Abiturnote: 1,4). Das Schuljahr 2004-05 absolvierte ich in den USA an der Madison High School, South Dakota.

Im Oktober 2007 begann ich das Studium der Humanmedizin an der Georg-August-Universität Göttingen. Im September 2009 bestand ich den Ersten Abschnitt der Ärztlichen Prüfung (Note: 1,0).

Wissenschaftlich befasste ich mich seit 2010 mit „Immunomodulatory activity of murine keratinocyte-derived exosomes“ in der Klinik für Dermatologie, Venerologie und Allergologie der Universitätsmedizin Göttingen (Betreuer der Promotion: Prof. Mempel und Prof. Schön). Hierfür legte ich ein Forschungssemester ein, um mich ganz der experimentellen Arbeit widmen zu können. Die Ergebnisse konnte ich bereits auf einem internationalen Kongress vorstellen und hierzu auch ein Reisestipendium einwerben: Tagung der European Society for Dermatological Research in Venedig 2012. Des Weiteren wurden Teile dieser Arbeit bereits publiziert (Kotzerke K, Mempel M, Aung T, Wulf GG, Urlaub H, Wenzel D, Schön MP, Braun A (2013): Immunostimulatory activity of murine keratinocyte-derived exosomes. Exp Dermatol 10, 650-655).

Das Praktische Jahr absolviere ich vom Februar 2013 bis zum Januar 2014 in der Abteilung Innere Medizin des Ameos Klinikums Alfeld, in der Abteilung Chirurgie des Krankenhauses Dresden-Friedrichstadt und in der Abteilung Neurologie des St. Bernward Krankenhauses Hildesheim.

Im Frühjahr 2014 werde ich voraussichtlich das Studium mit dem Zweiten Teil der Ärztlichen Prüfung abschließen. 


\section{Danksagung}

An erster Stelle danke ich Prof. M.P. Schön und Prof. M. Mempel, die mir diese Arbeit mit ihrer fachlichen Anleitung und ihrem Engagement ermöglicht haben. Vielen Dank!

Weiterer großer Dank geht an Dr. A. Braun, die mich in meinem Projekt direkt betreut und unterstützt hat: für stetige Motivation, konstruktive Problemlösung und hilfreiche Ratschläge. Ohne sie wäre diese Arbeit noch lange nicht fertig.

Zudem danke ich der gesamten Arbeitsgruppe Schön, insbesondere Dr. V. Lorenz und Dr. N. Pletz, ohne die so manches Experiment schiefgegangen und so manches Problem nie gelöst worden wäre. A. Bennemann danke ich für ihren unermüdlichen Einsatz bei unzähligen Experimenten die alleine logistisch nicht möglich gewesen wären. Großer Dank geht auch an A. Lockmann für die unzähligen (fachlichen) Diskussionen und die Unterstützung in der Zellkultur. Ein Dankeschön auch an A.-C. Hundt, Dr. K. Amschler, S. Forkel, K. Zachmann, B. Messerschmidt, U. Unkelbach und allen weiteren Labormitarbeitern.

Vielen Dank an Dr. D. Wenzel für die elektronenmikroskopischen Aufnahmen, Dr. H. Urlaub für die Proteomanalysen und J. Mahrt und Dr. J. Wessel für die Konfokalmikroskopie. Auch danken möchte ich D. Ellenberger, der mich in der statistischen Auswertung dieser Arbeit maßgeblich unterstützt hat, C. Baldini für die Bereitstellung und Anleitung bezüglich der Graphik-Computersoftware, sowie Prof. G.G. Wulff für die unkomplizierte Kooperation hinsichtlich der Ultrazentrifuge. 